\title{
Indicadores de Proximidad a Servicios Urbanos en la Ciudad de Heredia
}

\section{Indicators of Proximity to Urban Services in Heredia City, Costa Rica}

\author{
Marvin Alfaro-Sánchez ${ }^{1}$ \\ Marilyn Romero-Vargas ${ }^{2}$ \\ Tania Bermúdez-Rojas ${ }^{3}$ \\ Universidad Nacional, Costa Rica
}

http://dx.doi.org/10.15359/rgac.61-2.6

\section{RESUMEN}

Esta investigación trata sobre la cuantificación del acceso que tienen los residentes de la ciudad de Heredia a algunos servicios básicos en la ciudad, a partir de la distancia a la que viven, calculando que porcentaje de la población reside a 100,250,500.750,1000 y más de 1000 metros de distancia de la ubicación de los servicios. Los resultados obtenidos muestran un acceso heterogéneo a los servicios por parte de los residentes de la ciudad, lo cual es lo esperado en un área urbana que ha crecido y evolucionado en función de intereses económicos y comerciales, sin la intervención de un ente que planifique y regule las actividades en función del bienestar de la población residente.

1 Máster, Académico Escuela de Ciencias Geográficas de la Universidad Nacional, Costa Rica. Analista de indicadores de sostenibilidad urbana y experto en Sistemas de información Geográfica. Correo electrónico: marvin.alfaro.sanchez@una.cr.

2 Doctora, Académica Escuela de Ciencias Geográficas de la Universidad Nacional, Costa Rica. Analista de indicadores de sostenibilidad urbana y experta en paisajismo. Correo electrónico: marilyn.romero.vargas@una.cr.

3 Máster, Académica Escuela de Ciencias Biológicas de la Universidad Nacional, Costa Rica. Analista de indicadores de sostenibilidad urbana y experta en manejo y conservación de la biodiversidad. Correo electrónico: taniabermudez1@gmail.com.

Fecha de recepción: 22 de agosto de 2017

Fecha de aceptación: 22 de febrero de 2018 
Palabras clave: proximidad, accesibilidad, servicios, distancia, distribución de población.

\begin{abstract}
This research article considers the quantification of the access that residents of the city of Heredia have to some basic services in the city, taking as reference the distance to which the residents live, calculating what percentage of the population resides at 100,250,500,750,1000 $\mathrm{m}$ and more than $1000 \mathrm{~m}$ away from the location of the services. The results obtained show heterogeneous access to services by the residents of the city, which is expected in an urban area that has grown and evolved in response to economic and commercial interests, without the intervention of an entity to plan and regulate the activities based on the well-being of the resident population.
\end{abstract}

Keywords: proximity, accessibility, services, distance, distribution of the population.

\title{
Introducción
}

Cuando las ciudades tienen muchos y muy variados servicios, y cuando éstos son fácilmente accedidos por sus residentes, se promueve la comunicación y la integración entre ellos mismos y entre ellos y con las instituciones administrativas de las ciudades y cuando éstas implementan políticas que fomentan la peatonización (Del Campo, García \& Flores, 2009) y las relaciones ágiles y eficientes entre los distintos elementos del sistema urbano, se da como resultado una buena oferta de servicios y equipamientos básicos a una distancia suficientemente cercana como para ser recorrida a pie por los residentes, o con un sistema de transporte público que conecte todos los diferentes sectores de las ciudades.

La integración urbana es vital en procesos reales de sostenibilidad y debe ser una preocupación constante de las instituciones públicas que administran o gobiernan los espacios urbanos y una forma de determinar si los residentes de las ciudades tienen un buen acceso a los servicios urbanos, es mediante indicadores de proximidad.

\section{Marco Conceptual}

Para la Comisión Económica para América Latina (CEPAL), (2000) los servicios urbanos son las actividades que satisfacen las necesidades de una aglomeración humana, soportando y facilitando su funcionamiento y de ellos depende la capacidad de las ciudades de producir riqueza y de distribuirla entre sus habitantes. Los servicios son una consecuencia y, a la vez, una condición de esa aglomeración y de sus actividades en un territorio, ya que contrario a lo que sucede con las personas que residen de forma dispersa, que pueden satisfacer sus necesidades (agua, eliminación 
Marvin Alfaro-Sánchez, Marilyn Romero-Vargas. Indicadores de Proximidad a Servicios Urbanos en la Ciudad de Heredia

de desechos, etc.) individualmente, en una aglomeración urbana las necesidades deben ser atendidas en forma colectiva. Organization for Economic Co-Operation and Development. (OECD), (2000).

Dentro de este esquema, en Costa Rica, la Ley 4240 de Planificación Urbana (República de Costa Rica. 1962) clasifica los servicios, en forma indirecta, en dos categorías, los comunales (escuelas, colegios, parques, campos de juegos, unidades sanitarias, hospitales, bibliotecas, museos, mercados públicos, etc.) y los públicos (cañerías, alcantarillados sanitarios y pluviales, recolección y disposición de basuras), de explotación y/o financiamiento municipal y que deben estar incluidos en los planes reguladores locales (Pérez-Foguet. 2005), esta clasificación no involucra a todos aquellos otros servicios que no son indispensables, aunque si deseables, para los ciudadanos, como los sitios de entretenimiento (gimnasios, cines, teatros, museos y otros), o como los de servicios estéticos. (salones de belleza, acondicionamiento físico, etc.).

En esta investigación se analizará la proximidad de la población a algunos servicios públicos y comunales en la ciudad de Heredia, como indicadores de la accesibilidad que tienen los residentes de la ciudad a ellos, lo cual, está directamente relacionado con el modelo de ciudades compactas, complejas, eficientes y cohesionadas (Agencia de Ecología Urbana de Barcelona. 2010) que considera estos servicios como los elementos más importantes para medir el nivel de sostenibilidad de cualquier ciudad.

Las ciudades ofrecen una gran cantidad y variedad de servicios a sus ciudadanos y estos, según Pérez-Foguet (2005) propician el desarrollo de las aglomeraciones urbanas con coherencia en su organización territorial y con una alta cohesión social, en este sentido, desde un punto de vista ambiental, la cercanía a los diferentes servicios urbanos en una ciudad, reduce la necesidad y dependencia de los desplazamientos con vehículos privados y públicos y aumenta el número de desplazamientos a pie o a través de otros medios de transporte sostenibles, como la bicicleta, reduciendo el consumo de energía y las emisiones de gases de efecto invernadero, así como los niveles generales de contaminación atmosférica y acústica.

Desde el punto de vista social, la proximidad y cercanía a los servicios urbanos posibilita las buenas relaciones, una buena habitabilidad del espacio público y el desarrollo de un sentido de identidad en las comunidades, aumentando la cohesión social y la oportunidad de interrelación entre 
la ciudad y sus habitantes (Agencia de Ecología Urbana de Barcelona. 2010), sobre todo, cuando se complementa con políticas que fomentan la peatonización (Pérez-Foguet. 2005) y las relaciones ágiles y eficientes entre los distintos elementos del sistema urbano.

Chevalier, Choiniere y Bernier (1992) definen los indicadores como las medidas de la parte observable de un fenómeno, que permite valorar otras porciones no observables de dicho fenómeno, es decir, es lo que permite aproximarnos a un fenómeno que no se puede observar ni valorar en forma directa, por lo que, la proximidad a los servicios pueden ser usado como indicador de algo tan complejo como la sostenibilidad de las ciudades, bajo esta perspectiva, es importante y deseable, cuantificar que tan accesibles son los servicios que ofrecen las áreas urbanas para sus ciudadanos como indicadores del grado de sostenibilidad de la ciudad de Heredia.

Finalmente, es importante analizar el grado o nivel de proximidad a los servicios en las ciudades, ya que esto permite evaluar de una forma cuantitativa aspectos que están directamente relacionados con la calidad de vida de los ciudadanos y al mismo tiempo permite elegir la mejor ubicación para futuros nuevos servicios, mejorando la capacidad de toma de decisiones y aumentando la capacidad de evaluación del impacto de cualquier nuevo recurso o proyecto.

\section{Metodología para evaluar la proximidad a través del uso de indicadores}

Los indicadores de proximidad seleccionados relacionan la ubicación de los servicios públicos, la distribución de la población y la distancia a la que se encuentran unos de otros, para estos efectos se cuantificaron indicadores de proximidad a servicios públicos en las áreas de educación, salud, finanzas, transporte público colectivo, seguridad, ambiente, comercio y religión.

Cada indicador está calculado a partir del porcentaje de la población que reside a menos de 100 metros, entre 100 y 250 , entre 250 y 500 , entre 500 y 750 y más de 1000 metros de distancia de la ubicación donde se ofrece los servicios, excepto en el caso de la distancia a hidrantes, que se calculó siguiendo los parámetros internacionales de entidades dedicadas al desarrollo de redes de hidrantes, así como su instalación, operación y mantenimiento. 
Marvin Alfaro-Sánchez, Marilyn Romero-Vargas. Indicadores de Proximidad a Servicios Urbanos en la Ciudad de Heredia

Estos indicadores pueden ser de gran valor como herramientas para ejercicios de simulación. Por ejemplo, en el análisis de las preferencias en la localización de los hogares se espera que la distancia a los espacios verdes sea un factor importante en la selección final, así también la distancia a hidrantes debería de ser un elemento por considerar en el precio de seguros contra incendios.

\section{Resultados}

En la tabla 2 se presenta un resumen de los indicadores de proximidad estudiados en la ciudad de Heredia, donde se muestra el acceso que tiene la población a los servicios básicos urbanos.

Tabla 1. Resumen de los indicadores de proximidad en la ciudad de Heredia.

\begin{tabular}{|l|c|c|c|c|c|c|c|}
\hline & \multicolumn{7}{|c|}{ Distancia (metros) } \\
\hline & Menos de 100 & $\mathbf{1 0 0}$ - 250 & $\mathbf{2 5 0}$ - 500 & $\mathbf{5 0 0}$ - 750 & $\mathbf{7 5 0}$ - 1000 & Más de 1000 \\
\hline \multicolumn{1}{|c|}{ Indicador } & \multicolumn{6}{|c|}{ Porcentaje de población residente } \\
\hline Escuelas & 1,6 & 19,9 & 53,7 & 16,7 & 7,7 & 0,5 \\
\hline Colegios & 4,1 & 21,5 & 22,7 & 35,3 & 14 & 2,4 \\
\hline Áreas verdes & 1,2 & 12,9 & 33,8 & 28,2 & 15,6 & 8,3 \\
\hline Zona comercial & 16 & 20,9 & 35,4 & 16,2 & 5,5 & 5,9 \\
\hline Abarrotes & 31,7 & 42,7 & 12,6 & 5,7 & 3,6 & 3,6 \\
\hline Bancos & 1,2 & 9,6 & 28,8 & 32 & 16,3 & 12,1 \\
\hline Buses & 14,9 & 46,2 & 32,7 & 4,4 & 1,8 & 0 \\
\hline Taxis & 1 & 7 & 31 & 27 & 26 & 8 \\
\hline Hospitales & 1,7 & 4,7 & 22,7 & 18,1 & 13,1 & 39,8 \\
\hline Farmacias & 5,3 & 27,3 & 42,6 & 10,3 & 8,1 & 6,4 \\
\hline Hidrantes & 30,5 & 63,1 & 5,6 & 0,4 & 0,4 & 0 \\
\hline Policía & 0 & 2 & 5 & 10 & 14 & 69 \\
\hline Iglesias & 0 & 2,8 & 22,6 & 51,1 & 21,2 & 2,2 \\
\hline
\end{tabular}

Fuente: Elaboración propia, datos recolectados en junio 2017. 


\section{Indicador de proximidad a servicios educativos}

\section{a. Primaria}

Este indicador cuantifica el acceso que tiene la población a escuelas públicas del nivel primario. Como se puede observar en el mapa 1, la distribución de escuelas es relativamente homogénea en la ciudad de Heredia, aunque tienden a concentrarse en el centro, justo donde hay una baja densidad de residentes, por lo que la población que vive a una distancia menor a 100 metros de una escuela primaria es solo el 1\% del total de la ciudad (Gráfico 1).

Gráfico 1. Población residente a diferentes rangos de distancia a escuelas primarias en la ciudad de Heredia

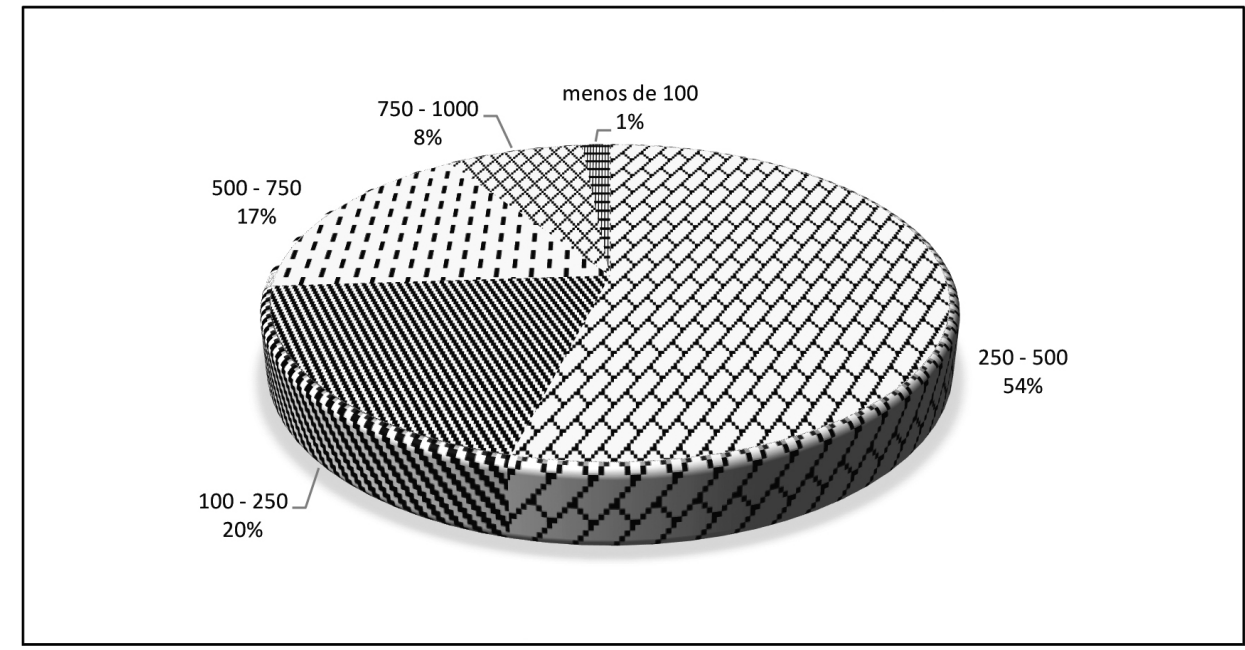

Fuente: Elaboración propia, datos recolectados en abril 2017. 
Mapa 1. Indicador de proximidad a escuelas primarias de la ciudad de Heredia

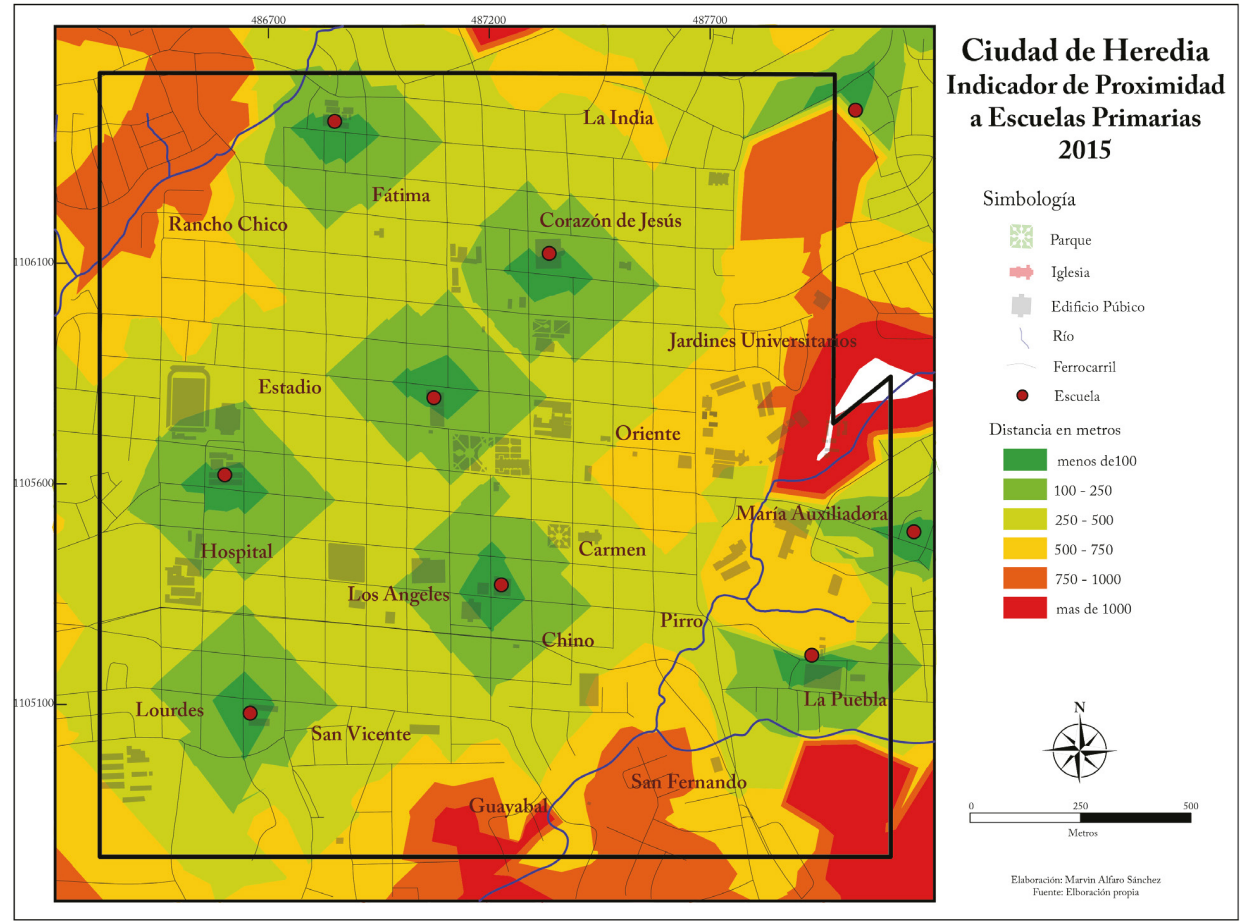

Fuente: Elaboración propia, datos recolectados en abril 2017.

Por otro lado, el 20\% de los residentes de la ciudad de Heredia tienen una escuela a una distancia de entre 100 y 250 metros, que según CATMED (2017), 250 metros es la distancia máxima que debería caminar un estudiante para llegar a su centro educativo, lo cual quiere decir que solo uno de cada cuatro posibles estudiantes tiene un buen acceso a esta facilidad urbana y que la mayoría (54\%) tiene que caminar hasta el doble de la distancia deseable. (Gráfico 1)

\section{b. Secundaria}

En la ciudad de Heredia hay solo tres instituciones públicas de educación de nivel medio (mapa 2), es decir, menos de la mitad de las ocho escuelas públicas de nivel primario que hay, y a pesar de que dos de esas tres instituciones se ubican en áreas con alta densidad de población, por 
lo que debería mejorar el acceso a la educación por proximidad a colegios para los residentes de la ciudad, sin embargo, no sucede dada la poca cantidad de colegios que existen en la ciudad.

Si se compara el acceso a la educación por proximidad a nivel primario y secundario se notan ciertas diferencias significativas. Los residentes de la ciudad que tienen un colegio a menos de 100 metros de distancia es el $2 \%$ (gráfico 2), mientras que para escuelas primarias era el 1\%, el 14\% de la población tiene un colegio a una distancia de entre 100 y 250 metros (considerablemente menos que los que tienen una escuela primaria a esa misma distancia, que es $20 \%$ ), sin embargo, el cambio más significativo se da en la población que reside a una distancia de entre 250 y 500 metros de un centro educativo, que es de $35 \%$ en secundaria y $54 \%$ en primaria.

Mapa 2. Indicador de proximidad a colegios en la ciudad de Heredia

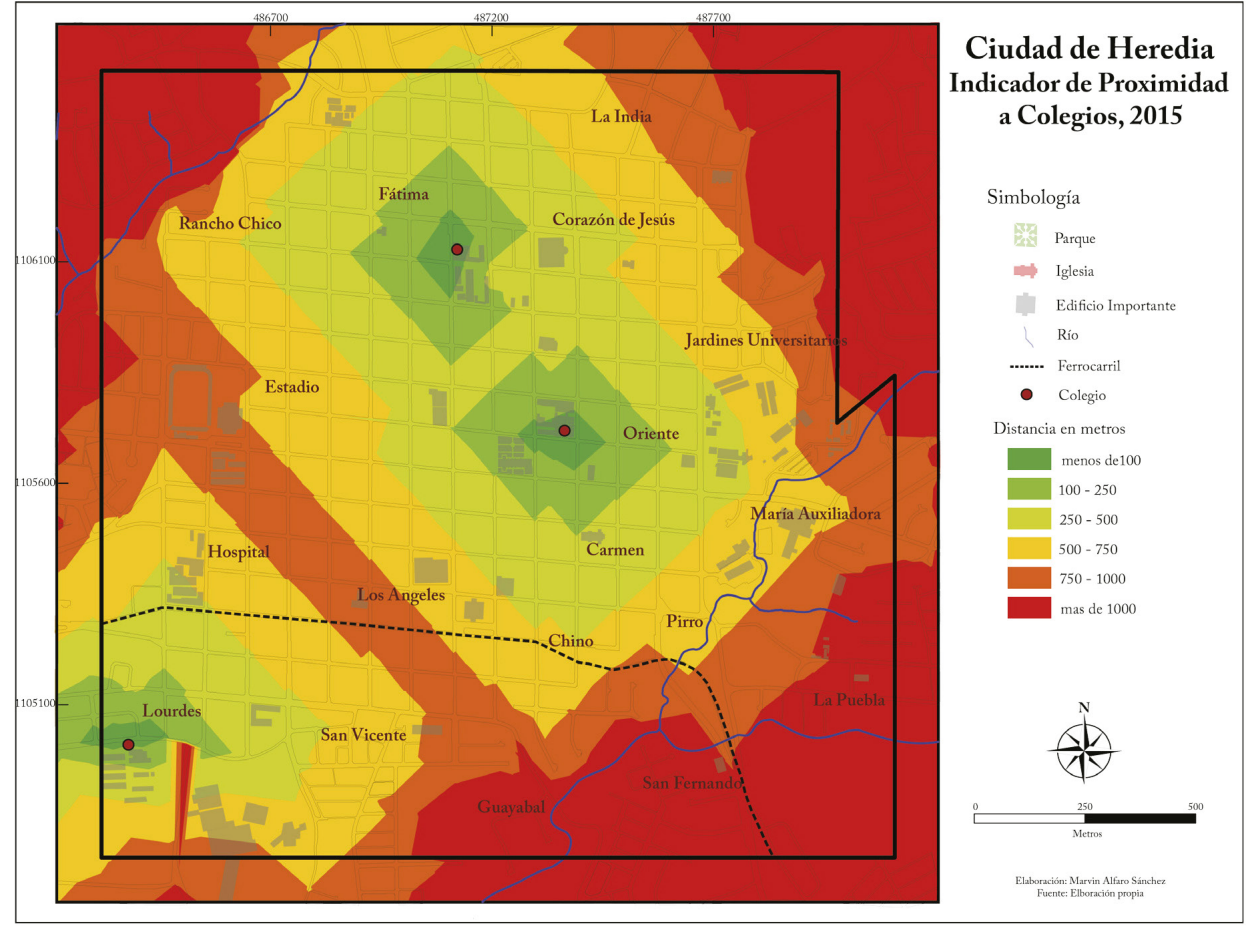

Fuente: Elaboración propia, datos recolectados en abril 2017. 
Marvin Alfaro-Sánchez, Marilyn Romero-Vargas. Indicadores de Proximidad a Servicios Urbanos en la Ciudad de Heredia

Sumando, solamente, los porcentajes de población que residen a las anteriores distancias de los centros educativos, se obtiene que un $75 \%$ de la población tiene una escuela a menos de 500 metros, pero solo el $61 \%$ tiene un colegio a la misma distancia, es decir, hay una considerable diferencia en este rango.

Tomando en cuenta las distancias superiores a 500 metros también se da un cambio significativo, para el 55\% de la población el colegio más próximo supera esa extensión, mientras que la población que tiene la escuela más próxima para ese mismo trecho es solo el $26 \%$, lo cual evidencia una baja sensible para el indicador de acceso a centros educativos entre un nivel y otro.

Gráfico 2. Población residente a diferentes rangos de distancia a colegios en la ciudad de Heredia.

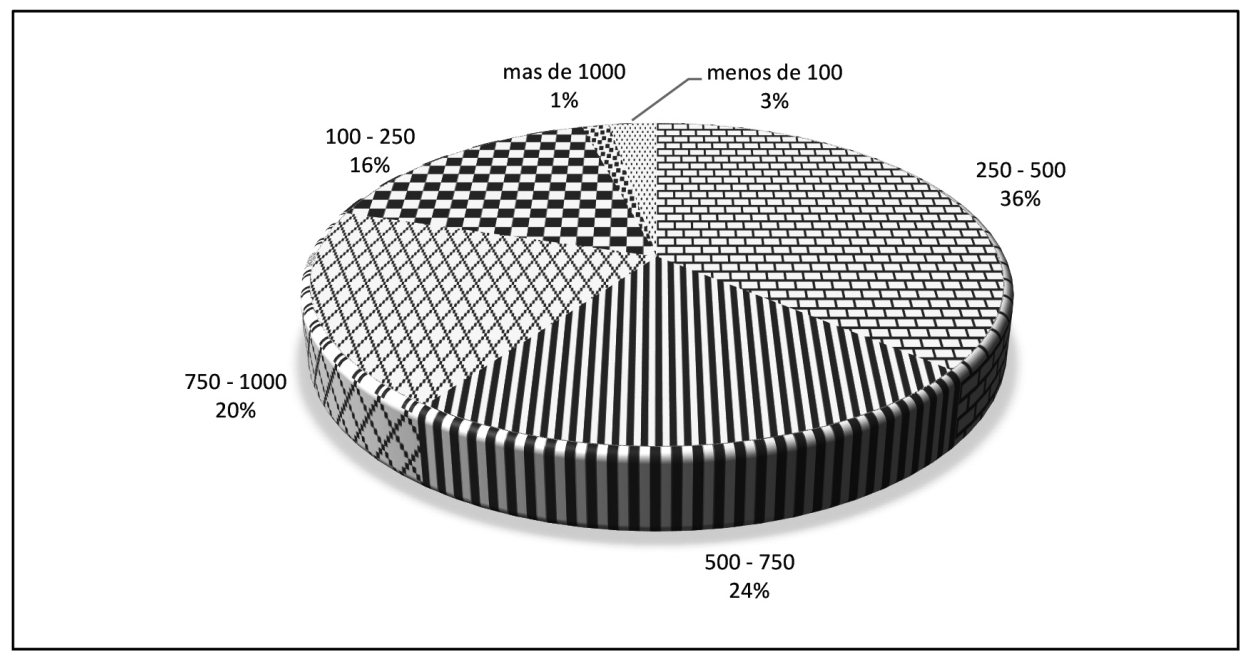

Fuente: Elaboración propia, datos recolectados en abril 2017.

\section{Indicador de proximidad a servicios ambientales}

\section{a. Espacios verdes}

Los espacios verdes públicos son notoriamente escasos en la ciudad de Heredia. Solo hay 3.13 metros cuadrados de áreas verdes por habitante, muy por debajo de los 10 metros cuadrados recomendados, como mínimo, por la Organización Mundial de la Salud y la proximidad a ellos tiene un 
comportamiento parecido a la de las escuelas primarias. Las áreas verdes tienden a concentrarse en las áreas centrales de la ciudad de Heredia, nuevamente, justo donde es más baja la densidad de habitantes. (Mapa 3)

Obviando los parámetros internacionales que determinan la distancia óptima a los espacios verdes en función de las distintas tipologías (Tabla 2), según su tamaño (de 50 hasta $150000 \mathrm{~m} 2$ ), es evidente que una proporción importante de la población está a una distancia poco deseada de los espacios verdes útiles. El 86\% de toda la población de la ciudad vive a una distancia superior a los 250 metros de distancia (Gráfico 3), que es, evidentemente, un trecho complicado para ciertos grupos sociales como los niños y los adultos mayores que deberían ser los usuarios con mayor accesibilidad a ellos, por la frecuencia con la que los visitan.

Tabla 2. Tipología de zonas verdes, según gobierno de la ciudad autónoma de Buenos Aires, 2010.

\begin{tabular}{|l|l|}
\hline \multicolumn{1}{|c|}{ Espacios verdes } & \multicolumn{1}{c|}{ Superficie m2 } \\
\hline Acupuntura urbana & 50 a 1.000 \\
\hline Plazas pequeñas & 1.000 a 5.000 \\
\hline Plazas & 5.000 a 15.000 \\
\hline Parque a escala urbana & 15.000 a 150.000 \\
\hline Parque a escala metropolitana & más de 150.000 \\
\hline
\end{tabular}

Fuente: Elaboración propia, datos recolectados en junio 2017. 
Marvin Alfaro-Sánchez, Marilyn Romero-Vargas. Indicadores de Proximidad a Servicios Urbanos en la Ciudad de Heredia

Mapa 3. Indicador de proximidad a áreas verdes en la ciudad de Heredia

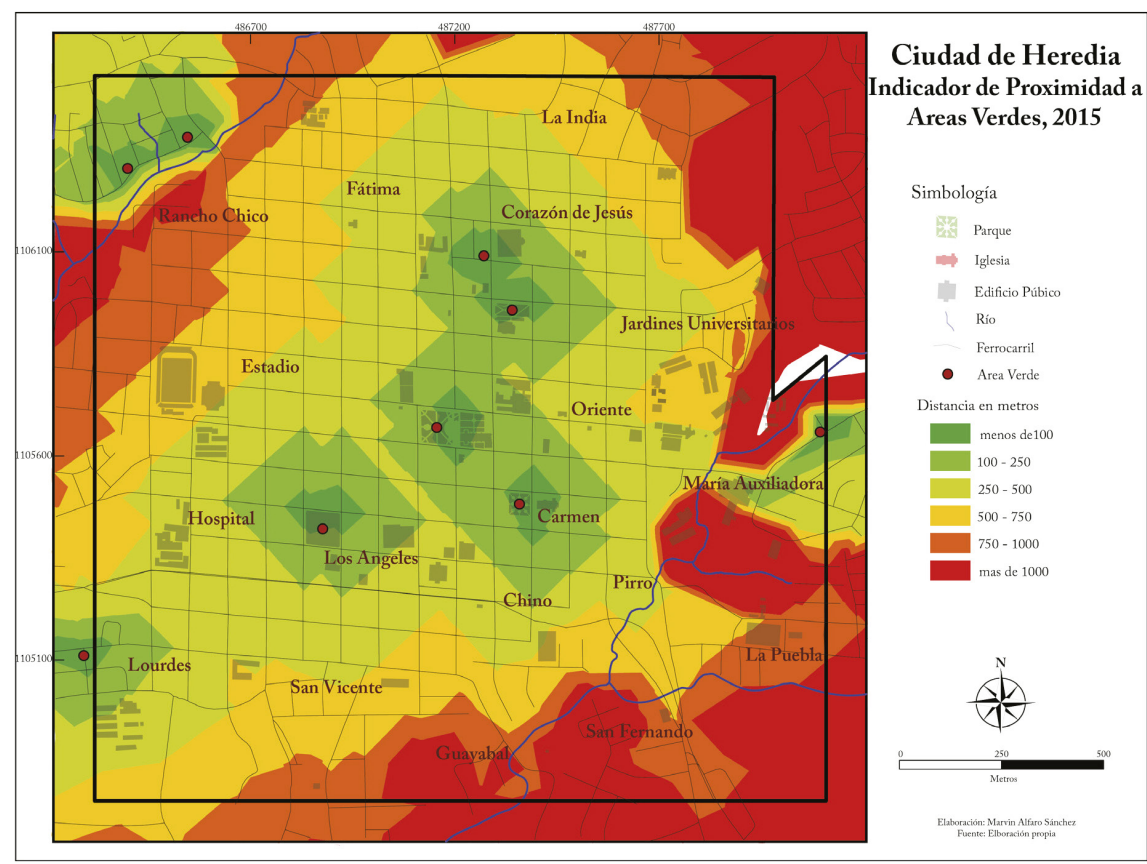

Fuente: Elaboración propia, datos recolectados en junio 2017.

Gráfico 3. Población residente a diferentes rangos de distancia a áreas verdes en la ciudad de Heredia.

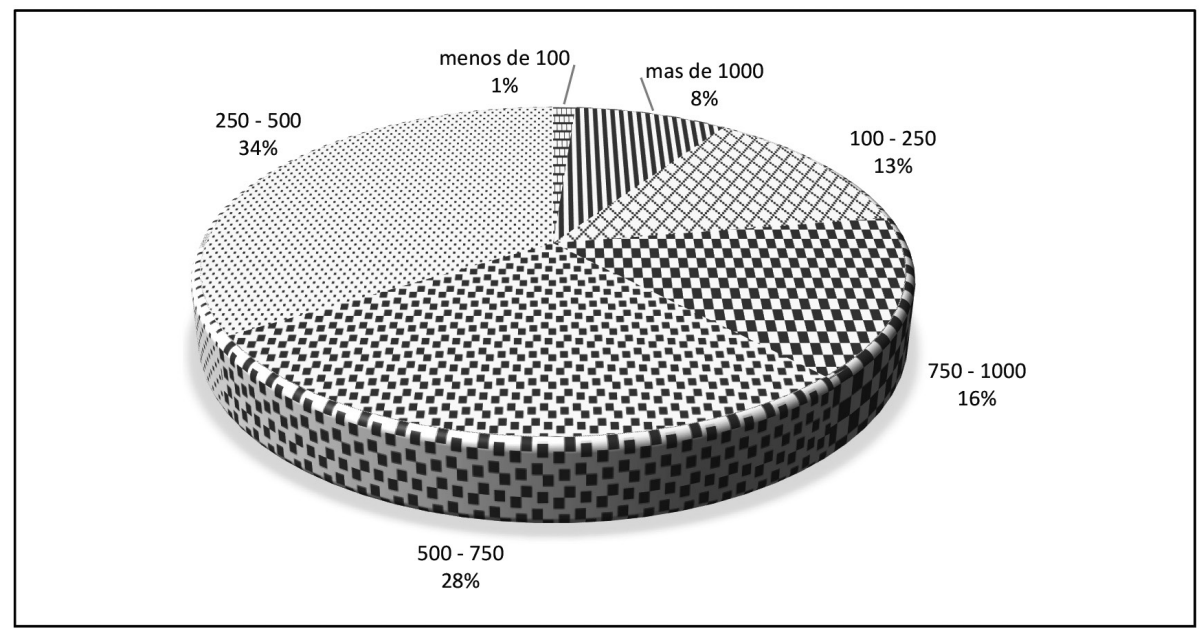

Fuente: Elaboración propia, datos recolectados en junio 2017. 


\section{3. ndicador de proximidad a servicios comerciales}

\section{a. Zonas comerciales}

La accesibilidad, por proximidad, a las zonas comerciales (mapa 4), está basada en la localización de las áreas con una densidad de veinte o más negocios comerciales por hectárea y la distancia a la que residen los habitantes de ellas. Aunque, al igual que como sucede con la proximidad a centros educativos y a áreas verdes, la zona comercial se ubica en el centro de la ciudad, donde la densidad poblacional es más baja, aunque si existe una mejor proximidad entre los servicios comerciales y los residentes que en los casos anteriores, ya que el $36 \%$ de los residentes de la ciudad viven a menos de 250 metros de distancia de las zonas comerciales (Gráfico 4), muy por encima del 21 y $14 \%$ de residentes que tienen acceso a escuelas primarias y a áreas verdes a esa misma distancia.

Mapa 4. Indicador de proximidad a zonas comerciales en la ciudad de Heredia.

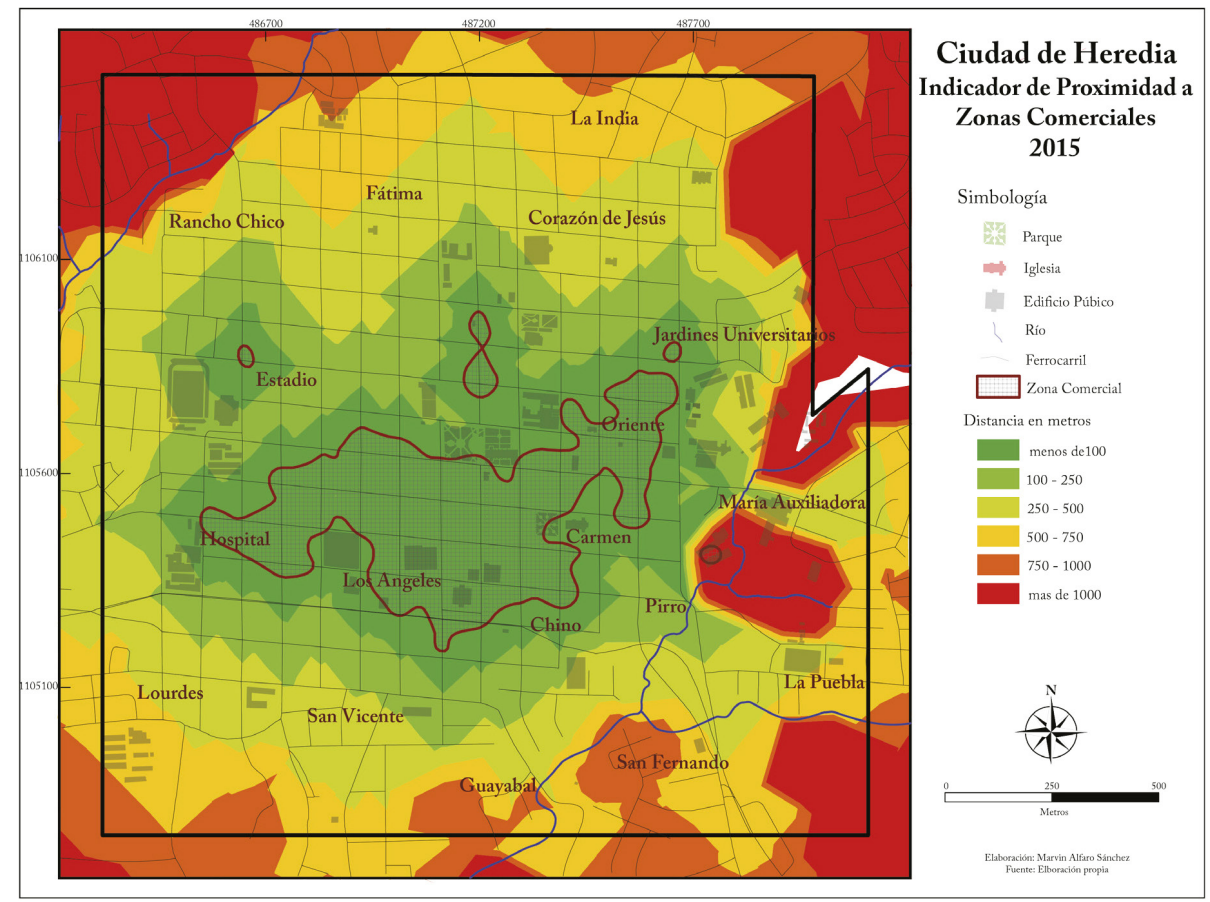

Fuente: Elaboración propia, datos recolectados en abril 2017. 
El rango de proximidad a las zonas comerciales con más población residente es el de 250 a 500 metros que tiene el $35 \%$ de los residentes de la ciudad, que si se suma con los dos rangos de distancia menores, nos indica que el $71 \%$ de la población debe caminar un máximo de 500 metros para acceder a las zonas comerciales de la ciudad que, desde cualquier ángulo que se analice es buen indicador de proximidad.

Gráfico 4. Población residente a diferentes rangos de distancia a zonas comerciales en la ciudad de Heredia.

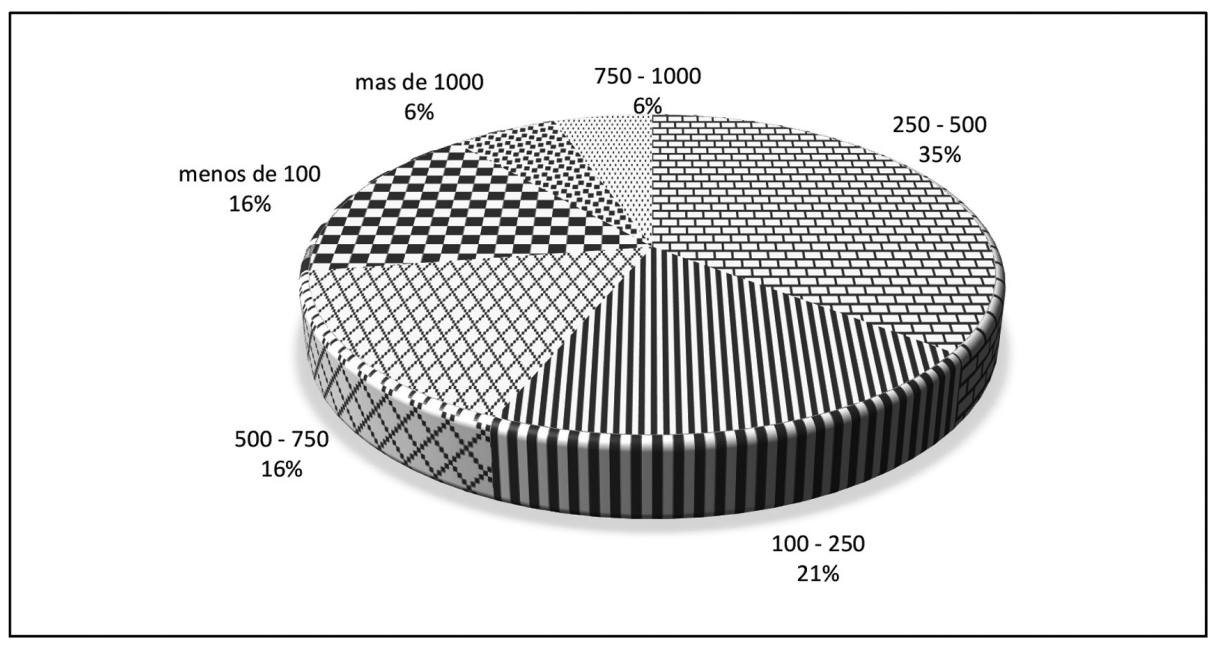

Fuente: Elaboración propia, datos recolectados en abril 2017.

\section{b. Indicador de proximidad a tiendas de abarrotes}

En el mapa 5 se observa la accesibilidad por proximidad a tiendas de abarrotes que tienen los residentes de la ciudad de Heredia, que contrario a lo encontrado con otros indicadores (escuelas, áreas verdes, etc.) las tiendas de abarrotes tienen una distribución más homogénea en la ciudad de Heredia y aunque hay sectores (3\% de la población) que se encuentran a más de 1000 metros de distancia de algún supermercado o negocio similar, la accesibilidad por proximidad a las tiendas de abarrotes es la segunda más alta, de las calculadas en esta investigación. (Gráfico 5)

La accesibilidad por proximidad es considerada alta porque el $76 \%$ de los residentes de la ciudad de Heredia tiene una tienda de abarrotes a menos de 250 metros de distancia de su residencia, lo cual es 
significativamente bueno para algunos grupos etarios como los ancianos que tienen una capacidad de caminar y de cargar peso más limitada que los otros grupos.

Gráfico 5. Población residente a diferentes rangos de distancia a tiendas de abarrotes en la ciudad de Heredia

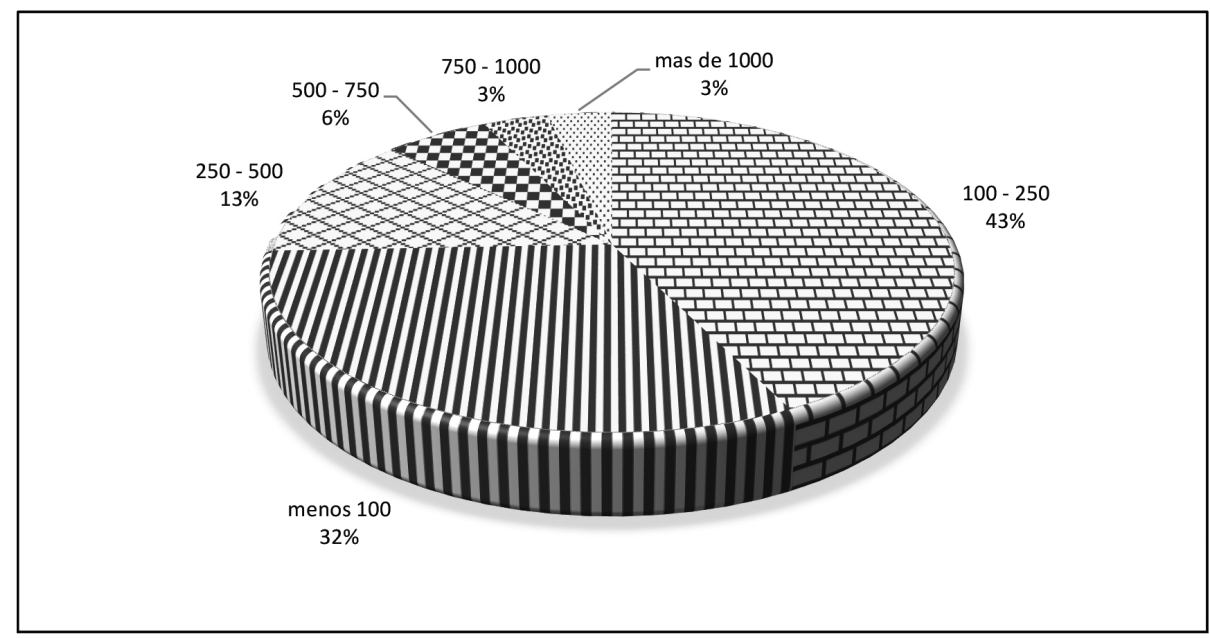

Fuente: Elaboración propia, datos recolectados en mayo 2017. 
Marvin Alfaro-Sánchez, Marilyn Romero-Vargas. Indicadores de Proximidad a Servicios Urbanos en la Ciudad de Heredia

Mapa 5. Indicador de proximidad a tiendas de abarrotes en la ciudad de Heredia

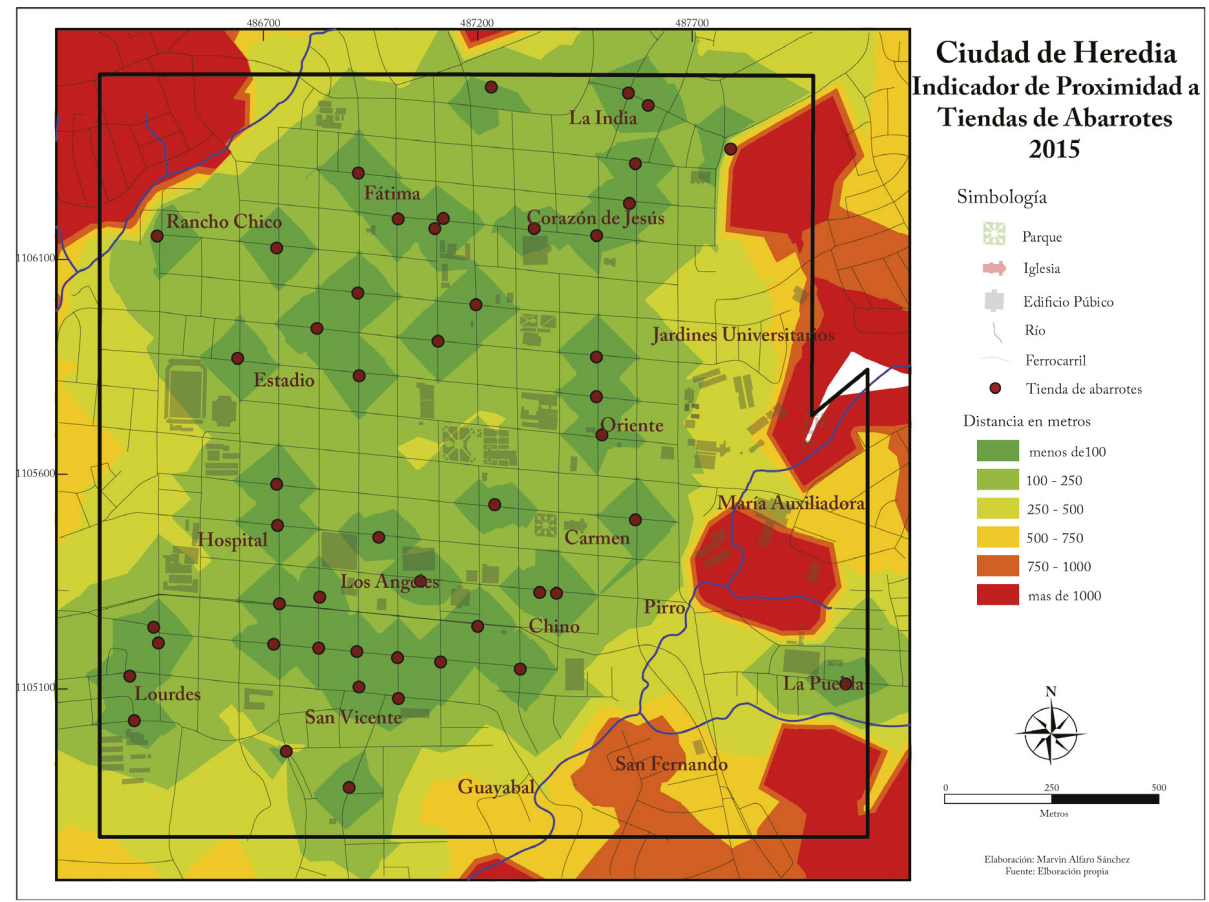

Fuente: Elaboración propia, datos recolectados en mayo 2017.

\section{Indicador de proximidad a servicios financieros}

La accesibilidad a servicios financieros medida a partir de la proximidad a los bancos que tiene la población residente en la ciudad de Heredia se puede apreciar en el mapa 6. La distribución de los bancos tiene una concentración aún más alta en el centro de la ciudad que otros servicios como los de educación y el de acceso a áreas verdes. 
Gráfico 6. Población residente a diferentes rangos de distancia a bancos en la ciudad de Heredia.

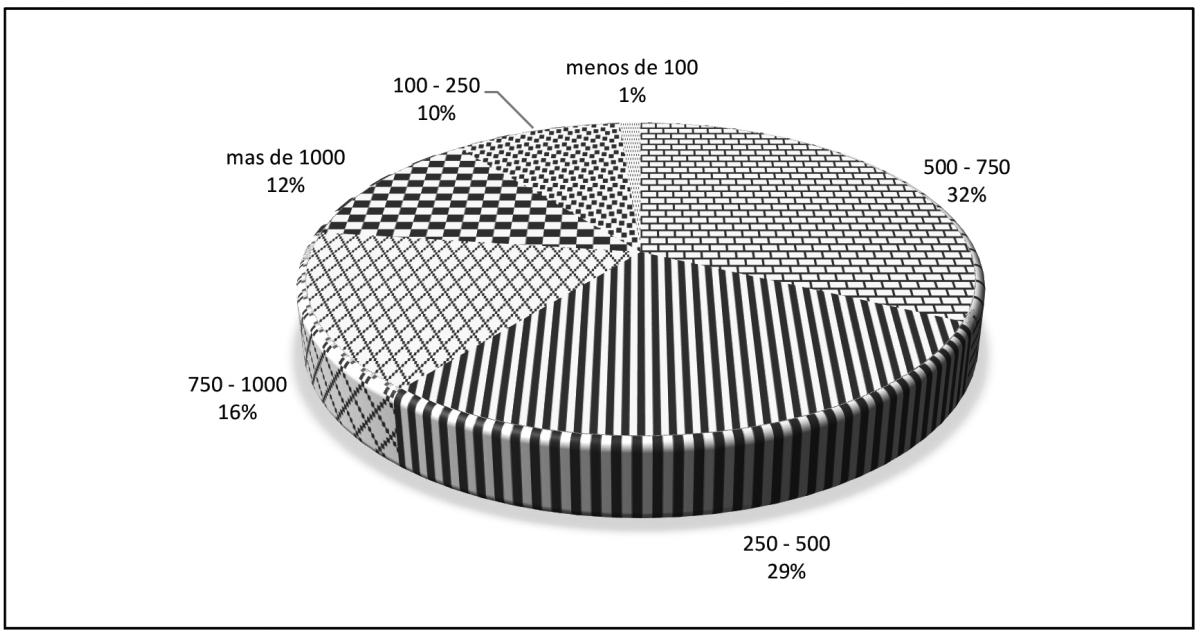

Fuente: Elaboración propia, datos recolectados en mayo 2017.

Mapa 6. Indicador de proximidad a bancos en la ciudad de Heredia.

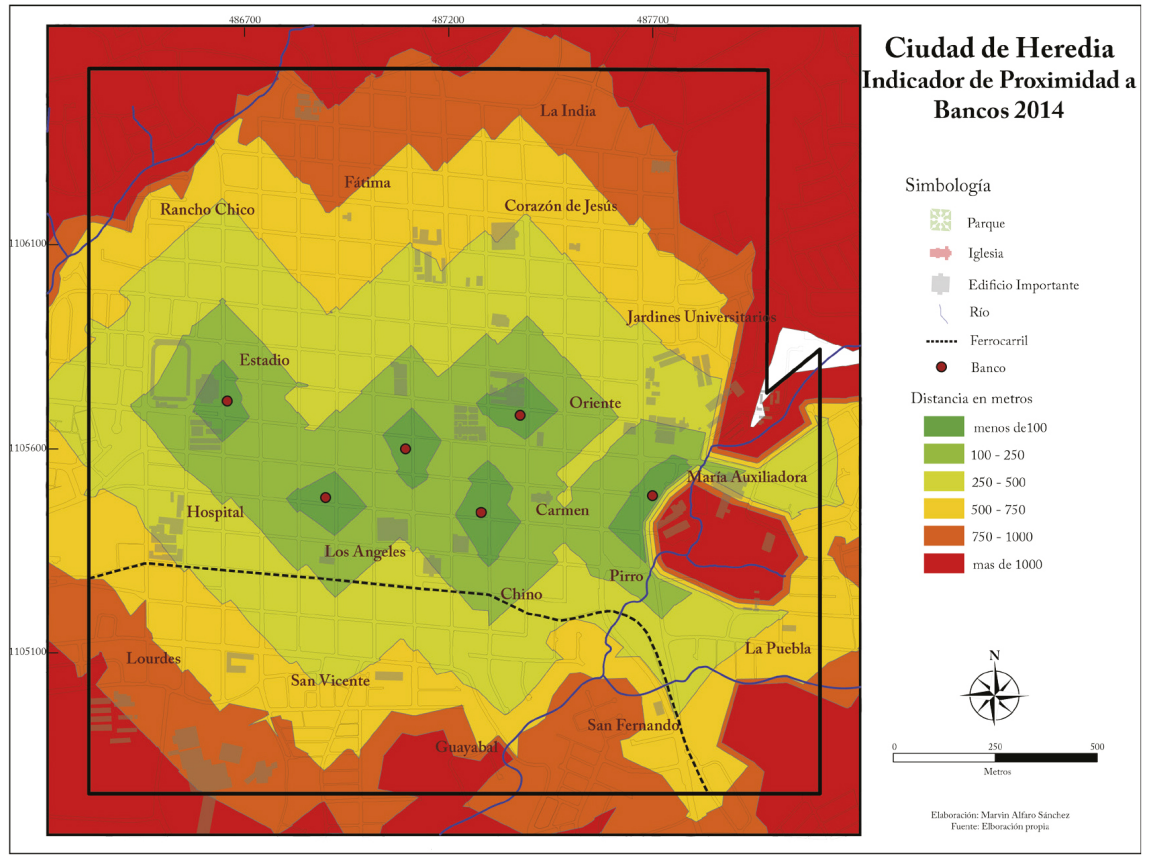

Fuente: Elaboración propia, datos recolectados en mayo 2017. 
La concentración espacial de los bancos en el área central de la ciudad de Heredia, donde la densidad de población es muy baja, hace que el acceso a ellos por parte de los residentes de la ciudad sea concéntrico y con valores muy bajos. Solo el $11 \%$ de los residentes de la ciudad tiene un banco a menos de 250 metros de distancia y solo un $1 \%$ a menos de 100 (gráfico 6), hay un porcentaje relativamente alto de población $(29 \%)$ que tiene un banco a una distancia moderadamente buena (entre 250 y 500 metros) y un porcentaje más alto (32\%) que tiene un banco a una distancia considerablemente alta (entre 500 y 750 ).

\section{Indicador de proximidad a servicios de transporte público}

\section{a. Paradas de buses}

En el mapa 7 se puede apreciar la accesibilidad por proximidad a las paradas de buses. La conectividad es claramente mayor en el centro de la ciudad donde se concentran las paradas, desde donde salen y a donde llegan la mayoría de rutas de buses que conectan la ciudad con otras ciudades, pueblos y barrios de otros distritos y cantones, y donde se encuentran las principales actividades financieras y comerciales de Heredia. Hacia la periferia de la ciudad disminuye la densidad de paradas disminuyendo el acceso a las líneas de transporte público.

En términos generales la accesibilidad al transporte público por proximidad a las paradas de buses es bastante alta en la ciudad de Heredia. Los residentes que tienen una parada de buses a menos de 100 metros de sus residencias es el $15 \%$ del total y los que la tienen a una distancia entre 100 y 250 metros es el $46 \%$, lo que en conjunto resulta que un $61 \%$ de los residentes de la ciudad caminan como máximo 250 metros para alcanzar una parada de bus (gráfico 7), la más alta proximidad a cualquiera de todos los servicios cuantificados en este documento. 
Mapa 7. Indicador de proximidad a paradas de buses en la ciudad de Heredia

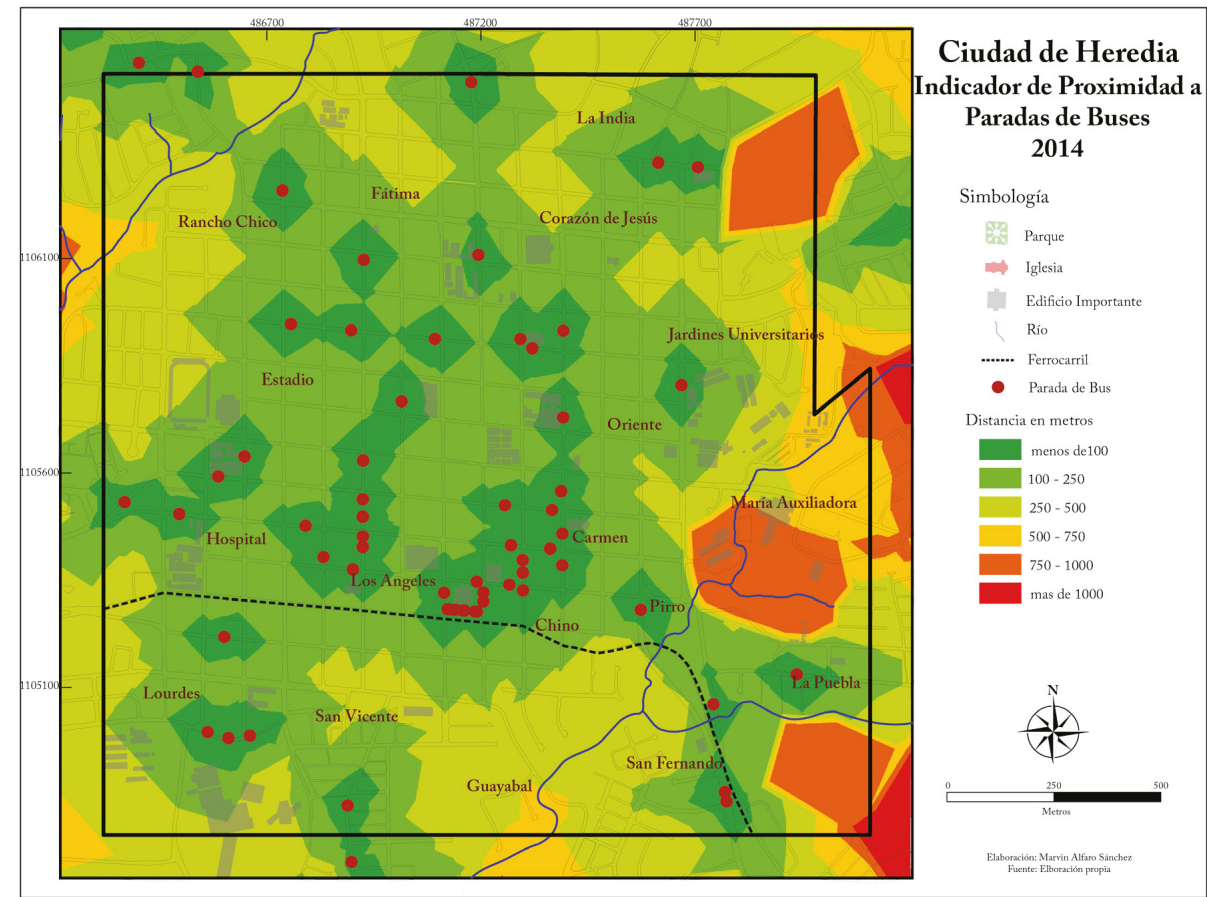

Fuente: Elaboración propia, datos recolectados en mayo 2017. 
Gráfico 7. Población residente a diferentes rangos de distancia a paradas de buses en la ciudad de Heredia

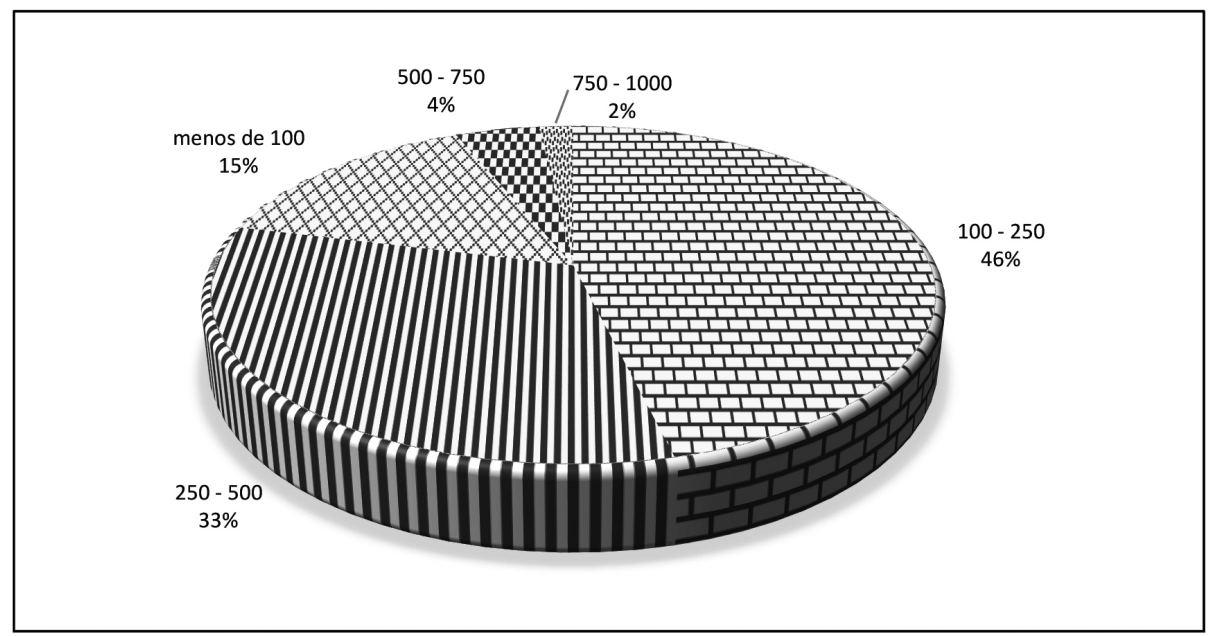

Fuente: Elaboración propia, datos recolectados en mayo 2017.

\section{b. Paradas de taxis}

Al igual que casi todos los otros servicios que se ofrecen en la ciudad de Heredia, las paradas de taxis están concentradas en el centro de la ciudad donde se desarrolla casi toda la actividad comercial y donde hay poca población residente. (Mapa 8)

Es obvio, que el acceso al transporte público usando el servicio de taxis, no se da exclusivamente en las paradas de ellos, pero si se toma como referencia el indicador de la proximidad por distancia a ellas que tiene la población, se puede observar muy claramente un comportamiento concéntrico partiendo desde la zona comercial de la ciudad, lo que hace que el acceso a este servicio urbano este en función de la distancia al centro de la ciudad en la que viven sus residentes. 
Mapa 8. Indicador de proximidad a paradas de taxis en la ciudad de Heredia

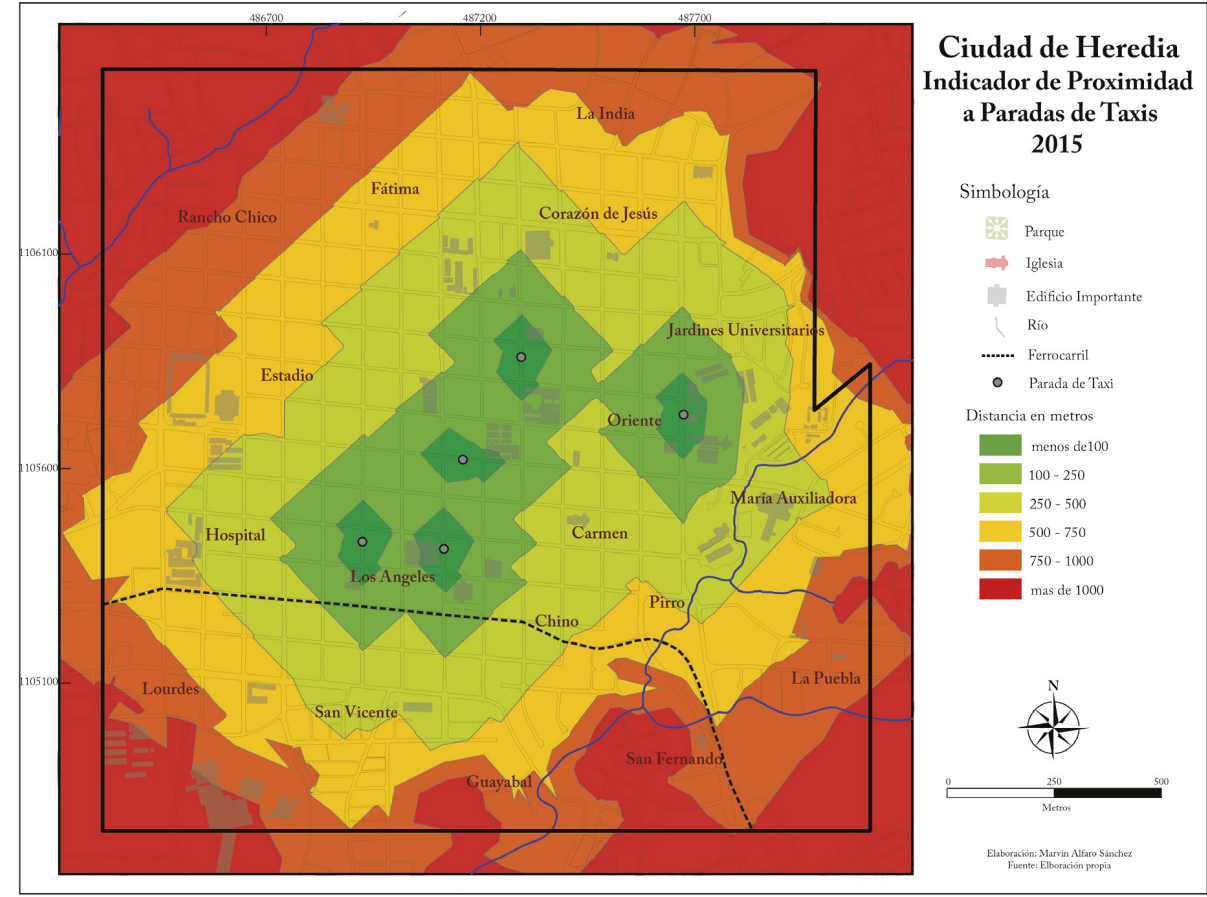

Fuente: Elaboración propia, datos recolectados en junio 2017. 
Marvin Alfaro-Sánchez, Marilyn Romero-Vargas. Indicadores de Proximidad a Servicios Urbanos en la Ciudad de Heredia

Gráfico 8. Población residente a diferentes rangos de distancia a paradas de taxis en la ciudad de Heredia.

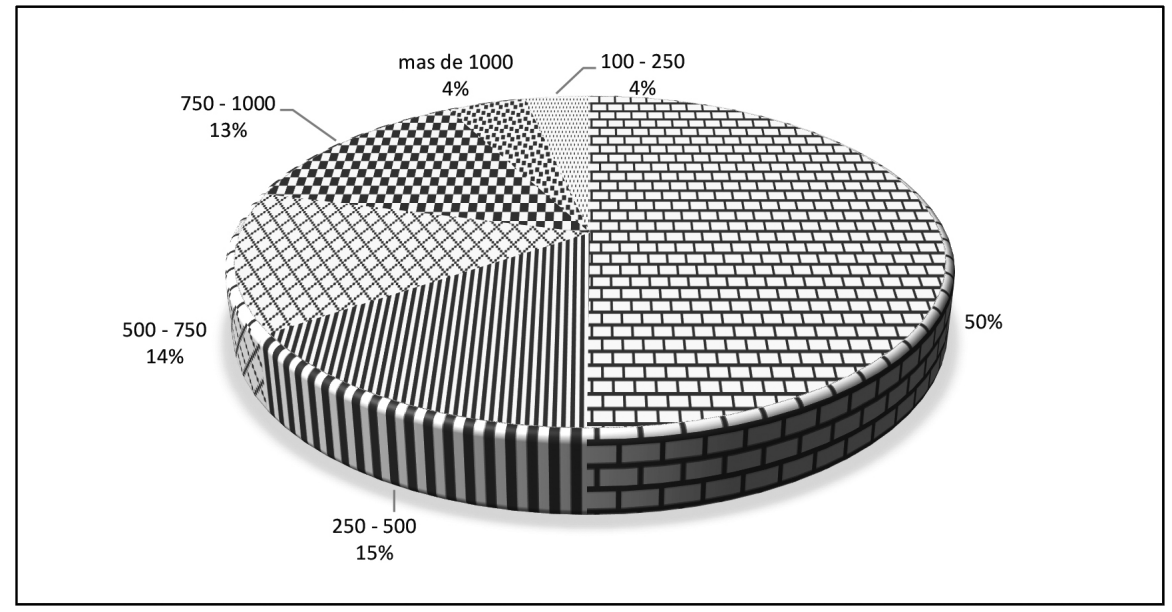

Fuente: Elaboración propia, datos recolectados en junio 2017.

\section{Indicador de proximidad a servicios de salud}

\section{a. Centros de atención médica}

Los servicios públicos de atención médica en la ciudad de Heredia, como en el resto del país, tienen dos componentes: la atención por consulta con cita previa, en lo que se denomina Equipos Básicos de Atención Integral en Salud (EBAIS), que atiende el control de enfermedades ya diagnosticadas, y la hospitalaria, que atiende emergencias, cirugías y enfermedades que requieren personal o equipo especializado para su atención, reuniendo ambos servicios en una sola variable, se tiene que la proximidad por distancia que tienen los residentes de la ciudad de Heredia a los servicios públicos de salud es bastante baja (gráfico 9). Solamente el 1\% de la población reside a menos de 100 metros de los centros de salud y un $5 \%$ lo hace a una distancia de entre 100 y 250 metros (gráfico 7) y esto está en función directa de la distribución de los centros de salud pública, que se concentran en un solo edificio al oeste de la ciudad. (Mapa 9)

Los bajos porcentajes de accesibilidad a los servicios de salud se ven ligeramente mitigados por el porcentaje relativamente alto de población residente a una distancia moderada de entre 250 y 500 metros, que es del $23 \%$ (casi uno de cuatro residentes), pero esto se anula parcialmente si se 
observa que para el $40 \%$ de la población residente en la ciudad los centros de salud se encuentran a más de 1000 metros de distancia.

Mapa 9. Indicador de proximidad a centros de salud en la ciudad de Heredia.

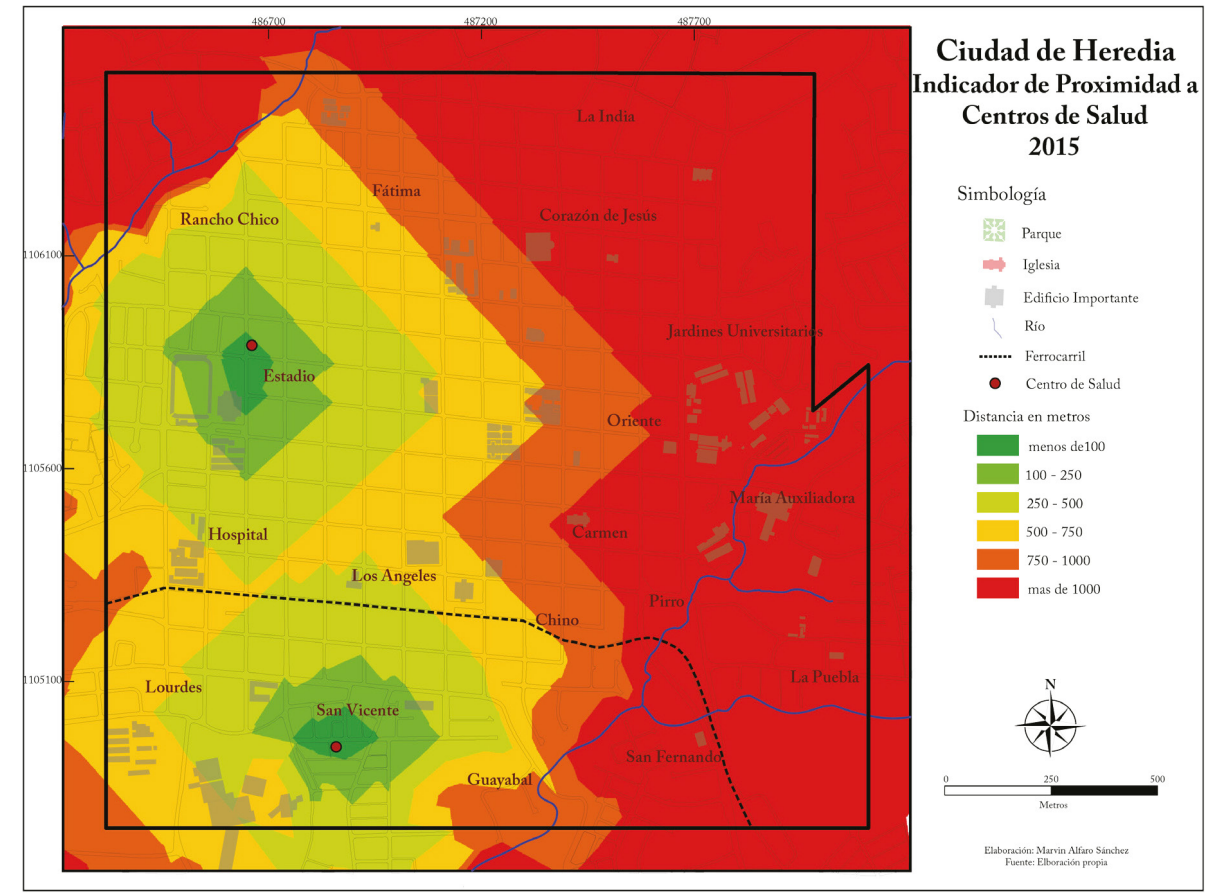

Fuente: Elaboración propia, datos recolectados en junio 2017. 
Marvin Alfaro-Sánchez, Marilyn Romero-Vargas. Indicadores de Proximidad a Servicios Urbanos en la Ciudad de Heredia

Gráfico 9. Población residente a diferentes rangos de distancia a centros de salud en la ciudad de Heredia.

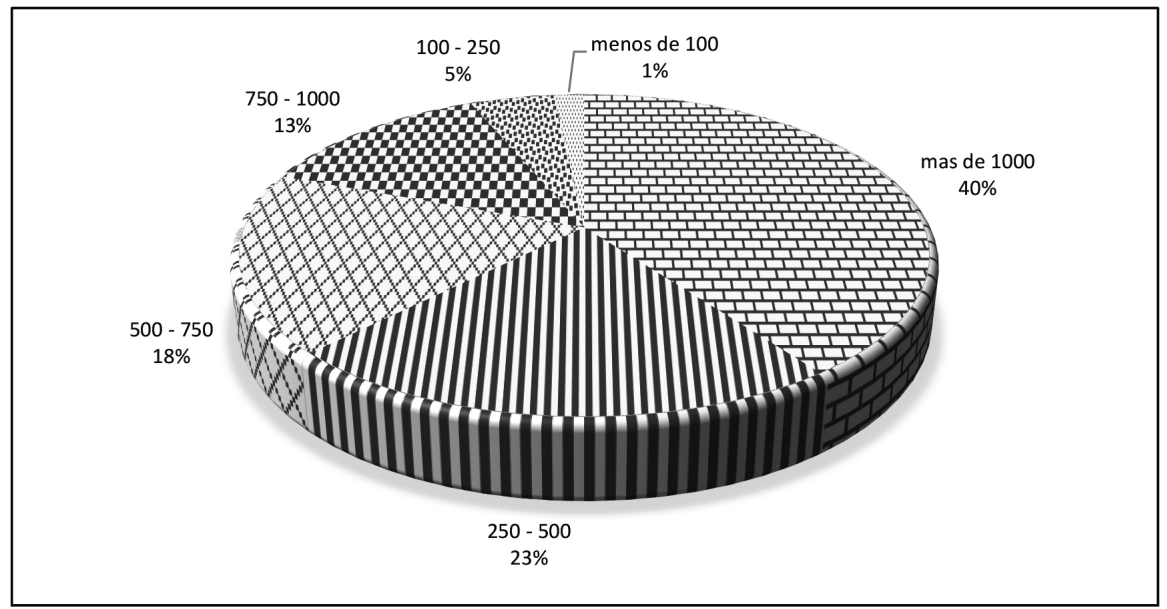

Fuente: Elaboración propia, datos recolectados en mayo 2017.

\section{b. Indicador de proximidad a farmacias}

En la ciudad de Heredia las farmacias, salvo unas cuantas excepciones, se localizan en el área comercial de la ciudad (mapa 10), por lo que el acceso a ellas por proximidad tiene valores solo un poco más altos que los de acceso a los otros servicios que se concentran, también, en el área comercial. 
Gráfico 10. Población residente a diferentes rangos de distancia a farmacias en la ciudad de Heredia

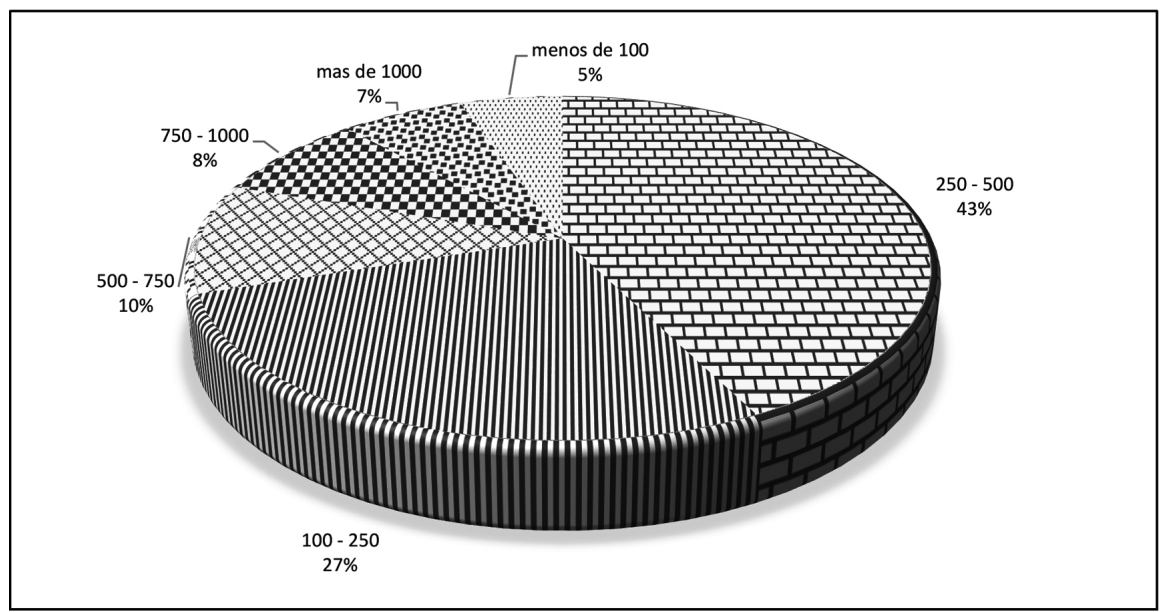

Fuente: Elaboración propia, datos recolectados en mayo 2017.

Mapa 10. Indicador de proximidad a farmacias en la ciudad de Heredia.

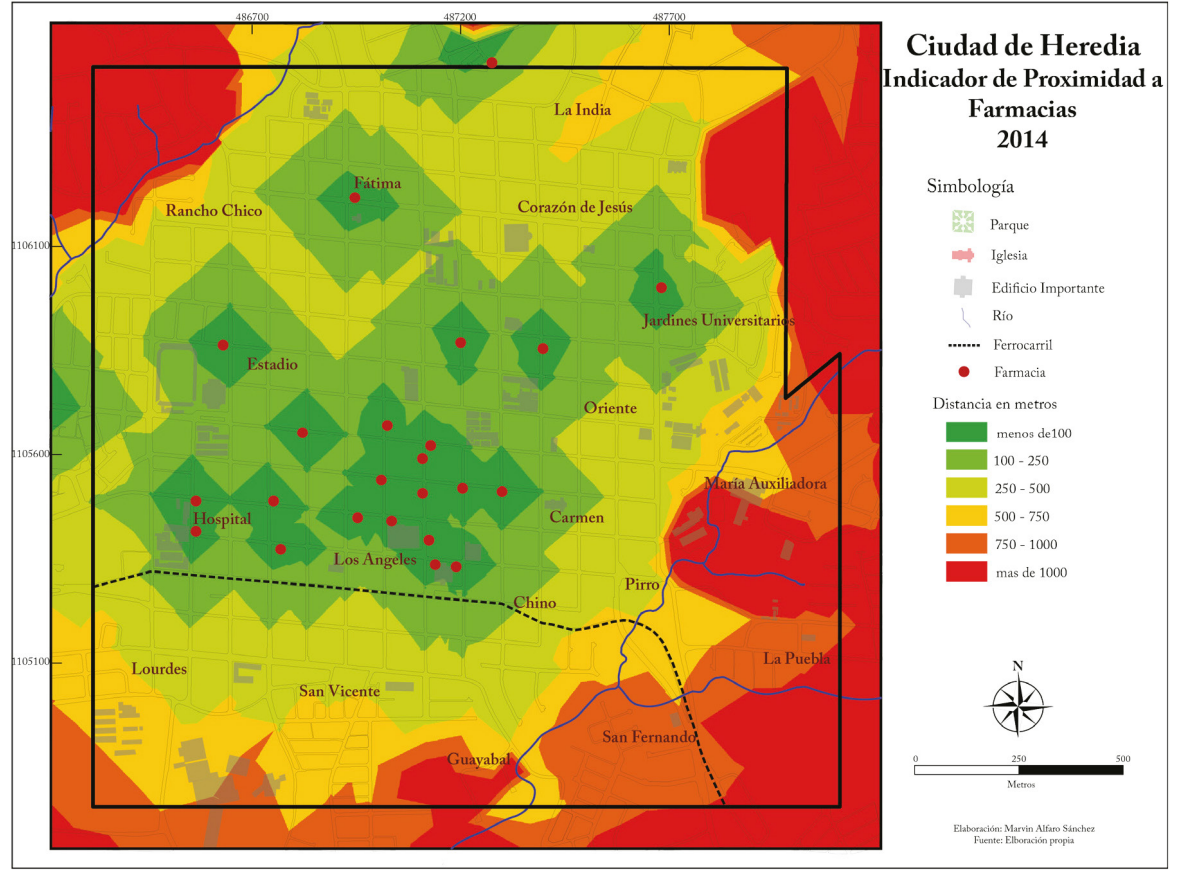

Fuente: Elaboración propia, datos recolectados en junio 2017. 
El porcentaje de población con mejor acceso al servicio de farmacias es de solo el 5\%, que reside a menos de 100 metros de ellas (gráfico 10), y un $27 \%$ de la población de la ciudad vive a una distancia que varía entre 100 y 250 metros, lo que sumado significa que casi uno de cada tres residentes tiene una farmacia a una distancia muy buena para recorrerla a pie y otro porcentaje alto de población (43\%) tiene una farmacia a una distancia relativamente buena (entre 250 y 500 metros), lo que en suma da que tres de cada cuatro residentes de Heredia deben caminar como máximo 500 metros para acceder a una farmacia.

\section{Indicador de proximidad servicios de seguridad ciudadana}

\section{a. Hidrantes}

El acceso por proximidad a los hidrantes, por la naturaleza de su uso, debe analizarse desde dos puntos de vista. Por un lado, su distribución espacial, que en la ciudad de Heredia es bastante homogénea (mapa 11), pero insuficiente, porque si sigue la norma 291 NFPA de la Asociación Norteamericana de Protección contra Incendios, adoptada por el Cuerpo de Bomberos de Costa Rica, que estima que la distancia lineal máxima entre hidrantes, en áreas urbanas, no debe ser superior a los 180 metros, solo el $53 \%$ de los 109 hidrantes tiene una distancia entre sí menor a ella, lo cual quiere decir que en el $47 \%$ de la ciudad no hay una cobertura aceptable de este tipo de dispositivo contra incendios.

Por otro lado, la proximidad por cercanía de las residencias de los ciudadanos a los hidrantes, que en este caso, a diferencia a los otros indicadores, se contabilizó los que residen a una distancia igual o inferior a 180 metros, es bastante buena, ya que un $68 \%$ de los residentes viven a menos de esa distancia de los hidrantes, es decir, casi siete de cada diez ciudadanos tienen un hidrante a la distancia idónea, según los parámetros del cuerpo de bomberos. (Gráfico 11) 
Mapa 11. Indicador de proximidad a hidrantes en la ciudad de Heredia.

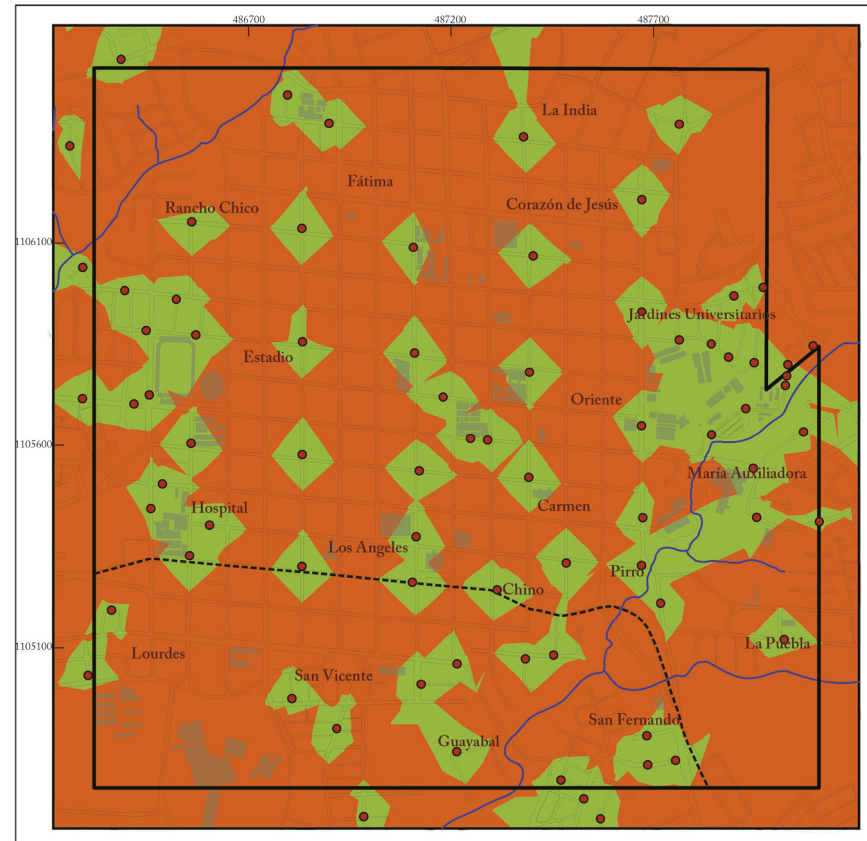

Ciudad de Heredia Cobertura de Hidrantes 2015
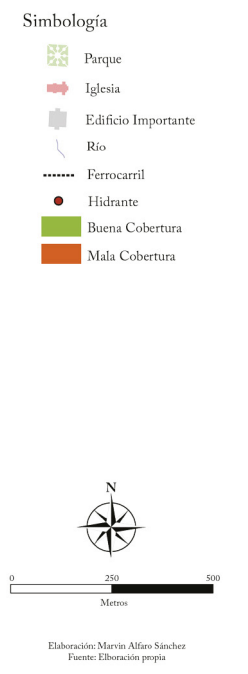

Fuente: Elaboración propia, datos recolectados en junio 2017.

Gráfico 11. Población residente a diferentes distancias de hidrantes en la ciudad de Heredia.

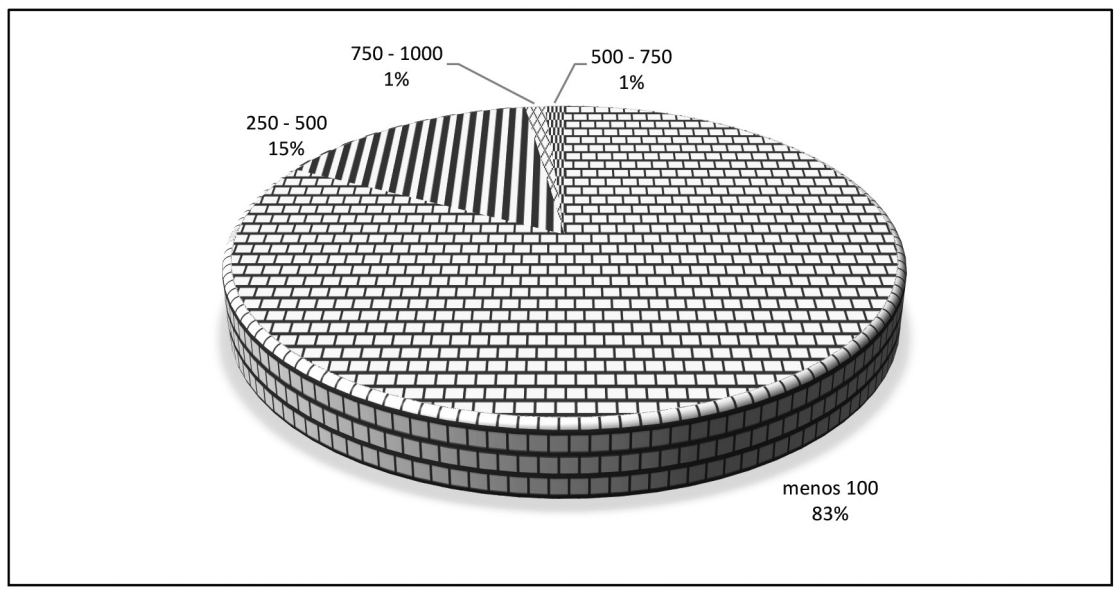

Fuente: Elaboración propia, datos recolectados en junio 2017. 
Marvin Alfaro-Sánchez, Marilyn Romero-Vargas. Indicadores de Proximidad a Servicios Urbanos en la Ciudad de Heredia

\section{b. Policía}

El acceso por proximidad, a una estación de policía en la ciudad de Heredia, es muy limitado, ya que solo existe una en toda la ciudad (mapa 12), por lo que, al igual que con el acceso a servicios de salud y otros, el acceso a los servicios de seguridad ciudadana es una función directa y concéntrica a partir de la ubicación de lo que se llama la comandancia de policía.

Siguiendo el mismo esquema de distancias, se tiene que, en la ciudad de Heredia, solamente el $2 \%$ de la población tiene una estación de policía a menos de 250 metros de distancia, que sería la distancia idónea según los lineamentos de esta investigación, un 10\% la tiene a menos de 750 metros y un 69\% a más de un kilómetro de distancia, es decir, que una patrulla o un policía debe desplazarse más de un kilómetro para llegar a siete de cada diez casas en la ciudad. (Gráfico 12)

Mapa 12. Indicador de proximidad a comandancia de policía en la ciudad de Heredia.

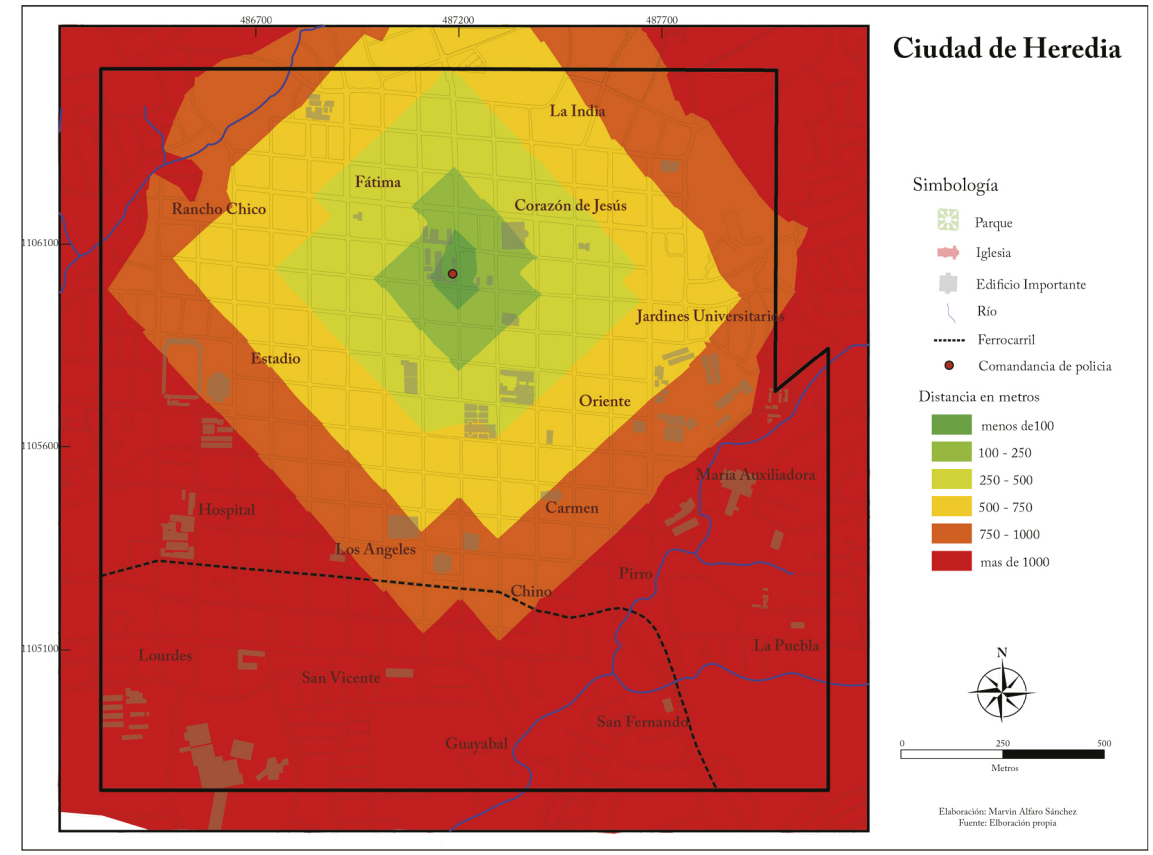

Fuente: Elaboración propia, datos recolectados en junio 2017. 
Gráfico 12. Población residente a diferentes distancias de comandancia de policía en la ciudad de Heredia.

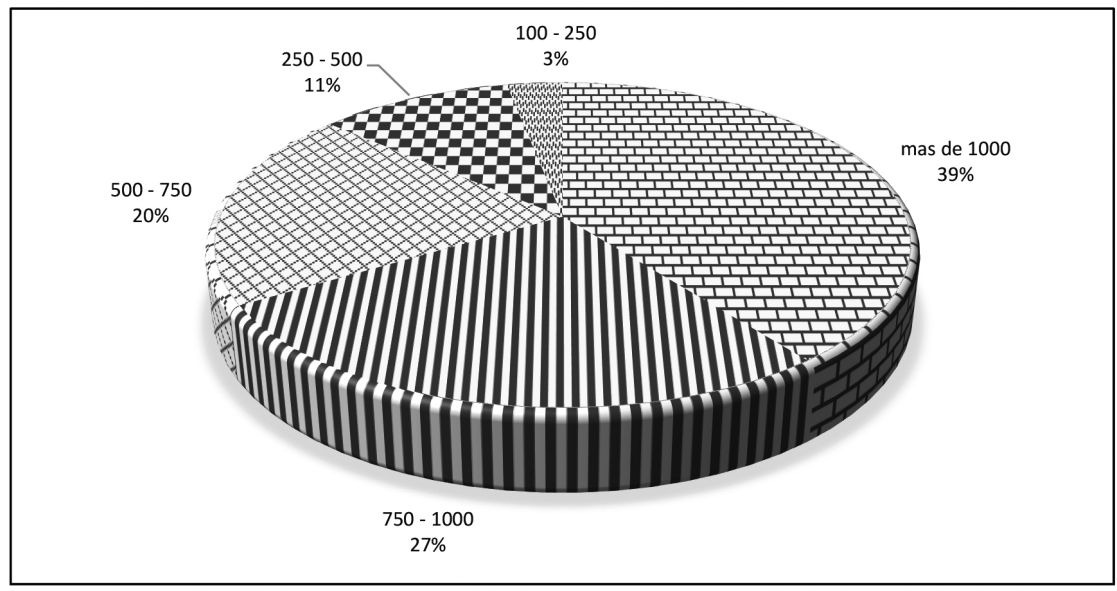

b Elaboración propia, datos recolectados en junio 2017.

\section{Indicadores de proximidad a servicios religiosos}

La proximidad, por cercanía, a servicios religiosos consideró, únicamente la distancia a iglesias católicas, porque esta es la fe que practica cerca del 76\% de los creyentes en Costa Rica (Madrigal, 2015) y al igual que en varios de los otros casos, la distribución de las iglesias católicas es bastante homogénea en la ciudad de Heredia (mapa 12), lo cual se traduce en una buena accesibilidad para la población, ya que el $23 \%$ de los ciudadanos viven a menos de 250 metros de una iglesia, es decir, casi uno de cada cuatro, mientras que los que viven a menos de 500 es el $74 \%$ de la población, lo cual representa casi tres de cada cuatro ciudadanos, (gráfico 12) y solamente $26 \%$ de la población debe desplazarse más de 500 metros para llegar a un centro religioso católico para satisfacer sus necesidades religiosas. 
Marvin Alfaro-Sánchez, Marilyn Romero-Vargas. Indicadores de Proximidad a Servicios Urbanos en la Ciudad de Heredia

Gráfico 13. Población residente a diferentes distancias a iglesias católicas en la ciudad de Heredia.

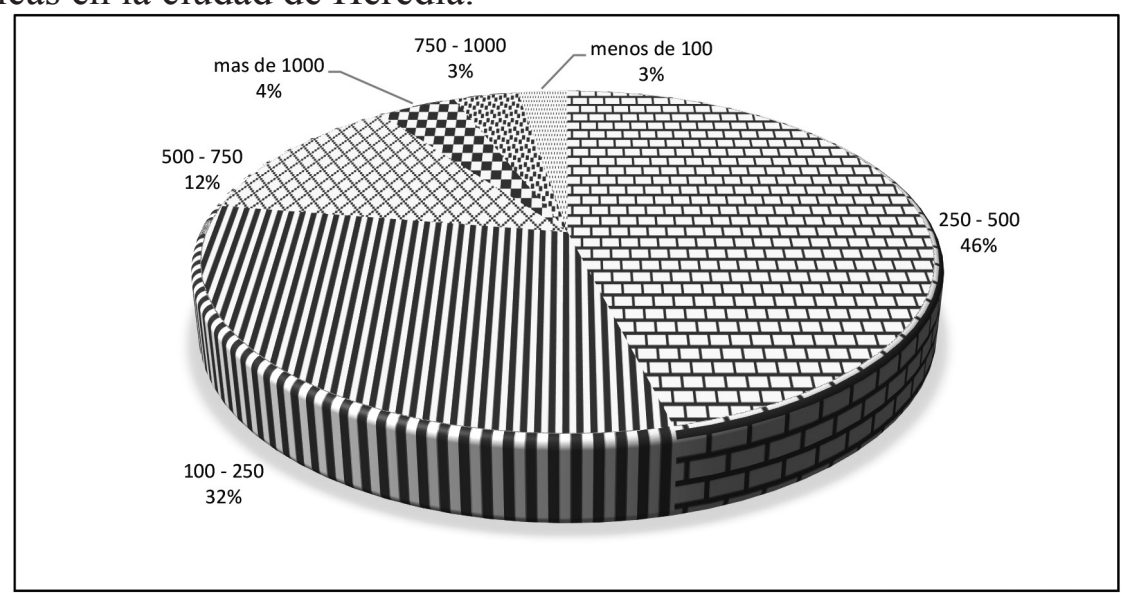

Fuente: Elaboración propia, datos recolectados en junio 2017.

Mapa 13. Indicador de proximidad a iglesias en la ciudad de Heredia.

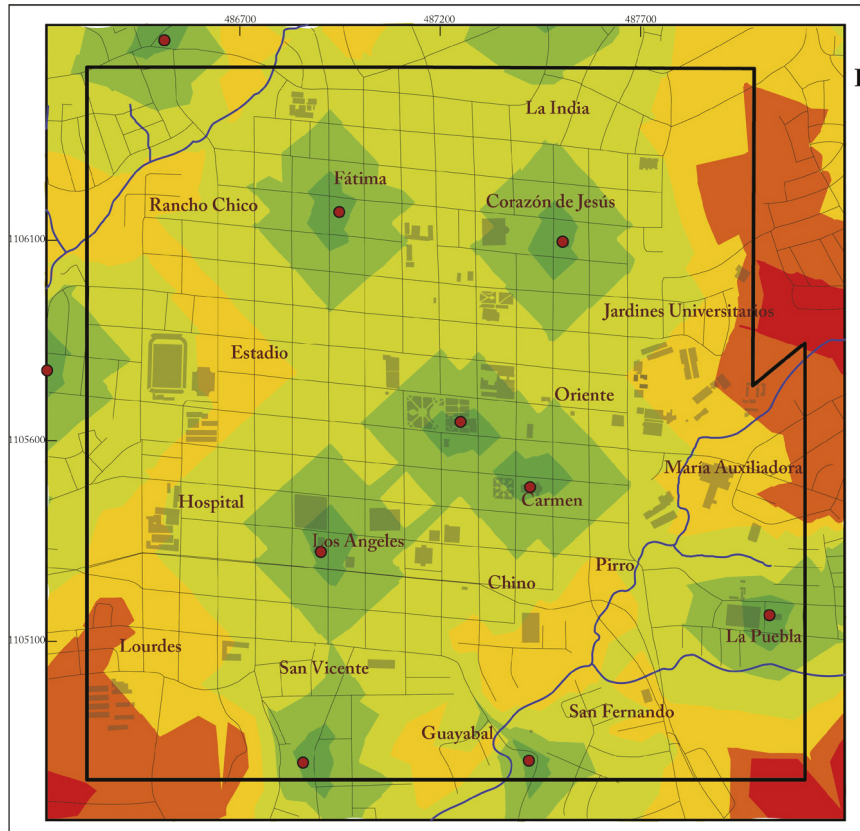

Ciudad de Heredia

Indicador de Proximidad

a Iglesias, 2015

Simbología

Pargave

$\Rightarrow$ Iglesia

14. Edificio Pübico

Rio

- Iglesia

Distancia en metros

menos de1 100
$100-250$

$250-500$

$500-750$

$750-1000$

mas de 1000

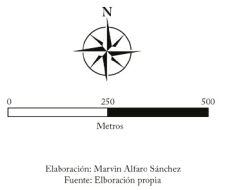

Fuente: Elaboración propia, datos recolectados en junio 2017. 


\section{Síntesis de resultados}

Aunque los indicadores, individualmente, fueron mapeados todos, no se puede hacer una sumatoria espacial (de mapas), pues cada servicio tiene un área de influencia diferente determinada por su localización y no hay forma de acumular proximidades a los servicios en función de la distancia que deben recorrer los residentes de la ciudad para accederlos.

Lo que sí puede hacerse, a modo de síntesis, es promediar las distancias que deben recorrer los residentes de la ciudad para acceder a los servicios, desde este punto de vista, se puede afirmar que los residentes de la ciudad de Heredia tienen un acceso modernamente bueno a los servicios urbanos que hay en la ciudad. En el gráfico 14 se resume y se simplifica la proximidad, medida por distancias, a los servicios. Un 30\% de todos los residentes, tienen que caminar menos de 250 metros para acceder a los servicios y un $27 \%$ de la población residente tiene un acceso calificado como regular a ellos, ya que en promedio deben caminar o desplazarse un máximo de 750 metros para acceder a los servicios presentes en la ciudad, en suma, un $57 \%$ de los residentes de la ciudad de Heredia tienen un acceso al menos aceptable a las facilidades urbanas en esta ciudad.

Lo anterior, muestra que la ciudad de Heredia puede ser calificada como un núcleo urbano en el que se puede, aún, realizar una mezcla de actividades, con residencia, en función de la proximidad a los servicios, lo que muestra que existen niveles buenos y aceptables de autocontención y autosuficiencia básicos en cualquier proceso de sostenibilidad y movilidad urbana. (Ayuntamiento de Sevilla. 2008) 
Marvin Alfaro-Sánchez, Marilyn Romero-Vargas. Indicadores de Proximidad a Servicios Urbanos en la Ciudad de Heredia

Gráfico 14. Población residente y el acceso promedio a los servicios en la ciudad de Heredia.

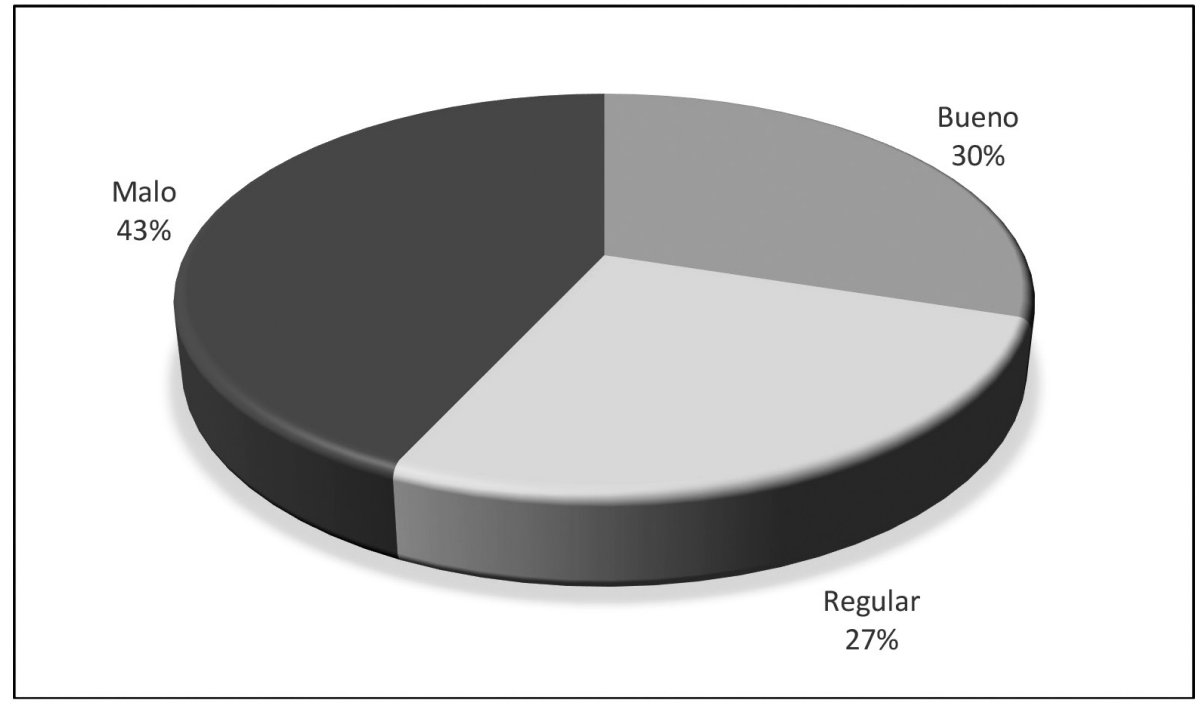

Fuente: Elaboración propia, datos recolectados en junio 2017.

\section{Conclusiones}

En esta investigación se midió únicamente el acceso por proximidad, que tiene la población residente en la ciudad de Heredia a algunos servicios y no se consideró la calidad de estos, que sin duda alguna es el complemento lógico e idóneo en una evaluación como esta, partiendo de esto es destacable la gran heterogeneidad en el acceso a los servicios en esta ciudad. Algunos indicadores presentan números muy positivos, como es el caso de los servicios comerciales, de tiendas de abarrotes o de acceso a hidrantes, mientras que otros no tanto, como es el de acceso a áreas verdes, servicios de salud o de seguridad ciudadana.

Dentro de los servicios con acceso más pobre está el de áreas verdes, hay un claro déficit de áreas verdes próximas a las zonas residenciales de la ciudad, nuevamente, sin considerar la calidad de ellas. La superficie de áreas verdes (parques, jardines públicos u otros) disponible por ciudadano $(3.1 \mathrm{~m} 2)$ está muy por debajo de las recomendaciones de la Organización Mundial de la Salud, que lo define entre 10 y $15 \mathrm{~m} 2$, y además de ser pocas, se ubican a distancias poco amigables para los residentes, con el 
agravante de que no existen predios desocupados en la ciudad en los que se puedan crear nuevos espacios verdes.

Los indicadores de proximidad a centros de salud y a estaciones de policía presentan, también, valores negativos, y ambos, muy posiblemente, por la misma razón. Los dos son servicios brindados por instituciones del gobierno central de Costa Rica que tienen administraciones muy centralizadas, tanto a nivel operativo como en términos de ubicación espacial, es decir, ambas centralizan sus operaciones en un solo edificio y no en centros pequeños distribuidos a lo largo de la ciudad, por lo que la población que vive cerca de ellos es relativamente poca con respecto al total de la ciudad.

Los otros indicadores de proximidad a servicios ofrecidos por el estado central como el de educación, tiene algunas características importantes de consideración. La ubicación de las escuelas y los colegios obedece a un proceso histórico que ya está desfasado, se ubicaron en su posición actual (en el centro de la ciudad) ya hace décadas, cuando había más población cerca de ellos, pero con los cambios en el uso de la tierra, especialmente, con el cambio de uso de residencial a comercial, estas instituciones se ubican hoy en día en áreas poco pobladas, por lo que los indicadores de proximidad presentan valores tendientes a bajos, y posiblemente con tendencia a seguir bajando con los futuros cambios en el uso de la tierra en los próximos años.

Es evidente, que el actual acceso a los servicios analizados en esta investigación, obedece a una dinámica histórica de la ciudad de Heredia, que ha sido dominada por intereses y actores económicos y que esta dinámica ha sido poco controlada por las instituciones públicas, resultando en una disparidad espacial casi anárquica de servicios urbanos, y que las necesidades de la población ha sido un factor irrelevante en la organización del territorio en la ciudad, por lo que es absolutamente necesario que las instituciones públicas intervengan más decidida y directamente en los patrones de distribución espacial de las diferentes actividades que se desarrollan en la ciudad, de modo que su crecimiento se oriente a mejorar el acceso a los servicios y con ello a mejorar la calidad de vida de los residentes a través de un mejor acceso a los servicios que toda ciudad debe ofrecer. 
Marvin Alfaro-Sánchez, Marilyn Romero-Vargas. Indicadores de Proximidad a Servicios Urbanos en la Ciudad de Heredia

\section{Referencias}

Agencia de Ecología Urbana de Barcelona. (2010). Plan de Indicadores de Sostenibilidad Urbana de Vitoria-Gasteiz. Barcelona, España Ayuntamiento de Sevilla. (2008). Plan Especial de Indicadores de Sostenibilidad Ambiental de la Actividad Urbanística de Sevilla, Barcelona, España.

CAT-MED (Plataforma). (2009). Urban Empathy. Recuperado de http:// www.catmed.eu/dic/es/61/proximidad-a-servicios-basicos.

Comisión Económica para América Latina. (CEPAL). (2000). Servicios urbanos y equidad en América Latina. Un panorama con base en algunos casos. División de Medio Ambiente y Asentamientos Humanos. Santiago, Chile.

Chevalier, S., Choiniere, R. y Bernier, L. (1992). User guide to 40 Community Health Indicators. Ottawa, Community Health Division. Health and Welfare Canada. Ottawa, Canadá

Del Campo, A., García, F. y Flores, M. (2009). Proceso de Peatonización y Nueva Sociabilidad. Centro de Estudios Andaluces. Sevilla, España. Ley 4240 de Planificación Urbana. (1962). República de Costa Rica. San José, Costa Rica.

Organization for Economic Co-Operation and Development. (OECD). (2000). Competition in Local Services: Solid Waste Management. Competition Policy Roundtables, ORGANISATION FOR ECONOMIC CO-OPERATION AND DEVELOPMENT.

Pérez-Foguet, A. (2005). Asentamientos Humanos e Infraestructuras de Servicios Urbanos. Associació Catalana d' Enginyeria Sense Fronteras. Barcelona, España. 